\title{
Constraining Particle Variation in Lunar Regolith for Simulant Design
}

\author{
Christian M. Schrader ${ }^{1}$ \\ BAE Systems, Marshall Space Flight Center, Huntsville, AL, 35805 \\ Doug Rickman ${ }^{2}$ \\ NASA, Marshall Space Flight Center, Huntsville, AL, 35812 \\ Douglas Stoeser ${ }^{3}$ \\ United States Geological Survey, Denver, CO, 80225 \\ Hans Hoelzer ${ }^{4}$ \\ Teledyne Brown Engineering, Huntsville, AL 35807
}

\begin{abstract}
Simulants are used by the lunar engineering community to develop and test technologies for In Situ Resource Utilization (ISRU), excavation and drilling, and for mitigation of hazards to machinery and human health. Working with the United States Geological Survey (USGS), other NASA centers, private industry and academia, Marshall Space Flight Center (MSFC) is leading NASA's lunar regolith simulant program. There are two main efforts: simulant production and simulant evaluation. This work requires a highly detailed understanding of regolith particle type, size, and shape distribution, and of bulk density. The project has developed Figure of Merit (FoM) algorithms to quantitatively compare these characteristics between two materials. The FoM can be used to compare two lunar regolith samples, regolith to simulant, or two parcels of simulant. In work presented here, we use the FoM algorithm to examine the variance of particle type in Apollo 16 highlands regolith core and surface samples. For this analysis we have used internally consistent particle type data for the 90-150 $\mathrm{\mu m}$ fraction of Apollo core 64001/64002 from station 4, core 60009/60010 from station 10, and surface samples from various Apollo 16 stations. We calculate mean modal compositions for each core and for the group of surface samples and quantitatively compare samples of each group to its mean as a measurement of within-group variance; we also calculate an FoM for every sample against the mean composition of 64001/64002. This gives variation with depth at two locations and between Apollo 16 stations. Of the tested groups, core 60009/60010 has the highest internal variance with an average FoM score of 0.76 and core 64001/64002 has the lowest with an average FoM of 0.92. The surface samples have a low but intermediate internal variance with an average FoM of 0.79. FoM's calculated against the 64001/64002 mean reference composition range from 0.79-0.97 for 64001/64002, from 0.41-0.91 for 60009/60010, and from 0.54-0.93 for the surface samples. Six samples fall below 0.70, and they are also the least mature (i.e., have the lowest $I_{s} / \mathrm{FeO}$ ). Because agglutinates are the dominant particle type and the agglutinate population increases with sample maturity $\left(I_{s} / \mathrm{FeO}\right)$, the maturity of the sample relative to the reference is a prime determinant of the particle type FoM score within these highland samples.
\end{abstract}

\section{Nomenclature}

FoM $\quad=$ Figure of Merit

\footnotetext{
${ }^{1}$ Geologist, National Space Science Technology Center, 320 Sparkman Drive

${ }^{2}$ Project Scientist, Earth Science Office/VP61.

${ }^{3}$ Research Geologist, Central Region Mineral Resources Team, MS973 Box 25046 DFC.

${ }^{4}$ Senior Systems Engineer, Engineered Systems, 300 Sparkman Dr., MS 134, AIAA Member.
} 


\section{Introduction}

$\mathrm{T}$ HERE has been a tremendous amount of data published on analysis of Apollo samples. Most of the regolithrelated work has addressed scientific questions of lunar crustal formation, geologic history, mixing and reworking from impact events, etc. The degree and kind of detail from this work is usually insufficient to adequately constrain lunar regolith parameters for engineering purposes. Constraining the expected variance as functions of distance of particle type, size and shape distribution, and bulk density of lunar regolith is paramount in designing processes and technologies for purposes of In Situ Resource Utilization (ISRU) and hazard mitigation.

The current lunar architecture puts the initial locus of habitation in the lunar Polar Regions, which are likely to be mantled by highlands-type lunar regolith. We are investigating Apollo 16 highland regolith samples to generate the data necessary to produce appropriate simulants and to evaluate simulants produced by other groups. ${ }^{1}$ Apollo cores, both drive and drill, are our preferred sample types - they allow for investigation of variation with depth and many proposed operations on the moon will involve excavation of lunar regolith to depths of tens of centimeters. As the lunar architecture expands or evolves, these investigations will expand to incorporate other lunar locales, such as mare and the KREEP-enriched Procellarium terrane.

There are numerous data in the literature that enable evaluations of variance in the regolith, though not always for the parameters we need. Examples include the sources of the datasets used in this paper, cited below, and extensive chemistry data. ${ }^{2-5}$ Furthermore, there have been studies specifically addressing chemical variance. ${ }^{6,7}$

In this paper we take particle type data (modal data) from the literature and analyze it using the Figure of Merit (FoM) tool developed by the simulant group to quantitatively compare reference regolith materials to simulants. ${ }^{8} \mathrm{By}$ this method we present new quantitative assessments of the particle type variance of Apollo 16 samples. Particle type modal composition is important for engineering as it strongly affects physiochemical processes like melting and oxidation/reduction. ${ }^{9,10}$ It also partly controls geomechanical behavior; minerals and glass have inherent characteristics of hardness and fracture/cleavage behavior reflective of their internal structure, and the behavior of the bulk material is partly derived from these constituents.

\section{Data}

\section{A. Dataset selection}

We selected the $90-150 \mu \mathrm{m}$ size grains because this is a size fraction for which a large number of samples have been analyzed using a compatible classification system of Ref. 11 . We were able to integrate some earlier work into this dataset, ${ }^{12,13}$ but at the cost of some loss of detail. Some data is available for fractions ranging from 20-1000 $\mu \mathrm{m},{ }^{12-14}$ some from 20-500 $\mu \mathrm{m},{ }^{15,16}$ and some only on the 90-150 $\mu \mathrm{m}$ fraction. ${ }^{14}$ Grains of from $90-150 \mu \mathrm{m}$ are generally identifiable under an optical microscope and broadly representative of the regolith composition. ${ }^{14} \mathrm{~A}$ summary of the data is shown in Table 1.

\section{B. Limitations}

The size distribution of particle types near the lunar surface changes with time. This "maturation" results from the competing processes of agglutinization and comminution of particles (path 1 of Ref. 17). Maturation results in a higher percentage of agglutinates and glass overall and an increase of mineral and glass fragments in the finest fractions at the expense of lithic and breccia fragments in the coarser size fractions. So, the examination of particle types in a given size fraction will not necessarily provide the same insight into regolith composition as will examination of a range of particle sizes in the same material.

Furthermore, there are important parameters of regolith composition that this exercise does not consider. One is the exact chemical composition of phases. Most minerals considered in this assessment are solid-solution minerals and these, as well as glass, have wide ranges of possible compositions. The actual chemical composition of solid solution minerals affects such things as melting temperature ${ }^{18}$. The current released version of the FoM algorithm does not adequately reflect this fact. Second, the published particle type modal data used here do not depict the total amount of any single phase in the regolith. For example, a mineral may occur as monomineralic particles, but it may also occur as grains in a particle of agglutinate, breccia, or a lithic fragment. This distinction in not captured by the available data. Third, the published data do not provide the level of detail on trace minerals in the regolith the FoM algorithm is designed to use. The term "opaques" (Table 1) is a catchall term for Fe metal, Fe-Ti minerals like 
ilmenite, spinel series oxide minerals that contain $\mathrm{Fe}, \mathrm{Ti}, \mathrm{Cr}, \mathrm{Al}$, and $\mathrm{Mg}$, and sulfide minerals. Other non-opaque trace minerals like the halogen-bearing phosphate apatite are not counted or are grouped under "miscellaneous" or "other". Although volumetrically minor, some of these trace minerals exert disproportionate harm to ISRU and mechanical processes (due to the $\mathrm{F}$ and $\mathrm{Cl}$ in apatite, or to the high abrasiveness of some spinel minerals) or disproportionate benefit to ISRU, such as the Fe-Ti oxide mineral ilmenite's benefit to oxygen production by $\mathrm{H}_{2}$ reduction.

\section{Figure of Merit}

The purpose of the Figure of Merit (FoM) is to quantitatively compare a regolith simulant to a reference material, where the reference may be a regolith sample, a hypothetical regolith sample, or other batches or types of simulants. However, the mathematics allows the comparison of any two materials. Though FoM algorithms exist for modal composition, size distribution, shape distribution, and density, we here compare materials only using the particle type, or modal composition, algorithm.

Table 1. Summary of literature data in \% for Apollo samples used in Figure of Merit calculations.

\begin{tabular}{|c|c|c|c|c|c|c|c|c|}
\hline \multirow[t]{2}{*}{ Samples } & \multicolumn{4}{|c|}{$64001 / 64002$ core $(n=12)^{15,16}$} & \multicolumn{4}{|c|}{ Apollo 16 surface soils $(n=15)^{14}$} \\
\hline & mean & $1 \sigma$ & $\max$ & $\min$. & mean & $1 \sigma$ & $\max$. & $\min$. \\
\hline Monomineralic & 23.5 & 8.1 & 42.5 & 13.7 & 22.9 & 10.0 & 46.0 & 8.2 \\
\hline plagioclase & 21.5 & 8.1 & 41.2 & 12.7 & 20.6 & 8.9 & 40.9 & 7.9 \\
\hline pyroxene & 1.7 & 1.2 & 5.0 & 0.7 & 2.1 & 1.6 & 4.7 & 0.3 \\
\hline olivine & 0.2 & 0.4 & 1.3 & & 0.2 & 0.3 & 0.7 & \\
\hline opaque & 0.1 & 0.1 & 0.3 & & 0.1 & 0.1 & 0.3 & \\
\hline $\mathrm{SiO} 2$ phase & 0.0 & 0.1 & 0.3 & & 0.0 & 0.1 & 0.3 & \\
\hline Crystalline Lithics & 0.7 & 0.5 & 1.5 & & 0.5 & 0.8 & 2.7 & \\
\hline Mare Basalt & 0.3 & 0.3 & 0.7 & & & & & \\
\hline KREEP Basalt & 0.1 & 0.2 & 0.6 & & & & & \\
\hline Breccias & 27.9 & 3.4 & 33.1 & 22.5 & 41.2 & 10.7 & 64.1 & 26.1 \\
\hline Fragmetnal/Vitric Matrix & 12.3 & 2.5 & 16.4 & 9.1 & 20.2 & 9.0 & 36.2 & 7.6 \\
\hline Crystalline matrix & 15.6 & 2.4 & 22.1 & 12.3 & 21.0 & 10.7 & 56.5 & 13.1 \\
\hline Agglutinates & 40.0 & 6.9 & 49.1 & 25.8 & 30.5 & 15.7 & 56.2 & 1.6 \\
\hline Glass & 7.8 & 2.0 & 11.7 & 4.6 & 4.8 & 3.0 & 10.6 & 0.9 \\
\hline Other & 0.1 & 0.2 & 0.6 & & & & & \\
\hline \multirow[t]{3}{*}{ Total } & 100.0 & & & & 100.0 & & & \\
\hline & \multicolumn{4}{|c|}{$60009 / 60010$ core $(n=11)^{12,13}$} & & & \multicolumn{2}{|c|}{ All samples } \\
\hline & mean & $1 \sigma$ & $\max$. & $\min$. & & & mean & $1 \sigma$ \\
\hline Monomineralic & 32.8 & 18.6 & 78.7 & 13.3 & & & 26.0 & 13.1 \\
\hline plagioclase & 29.8 & 18.6 & 76.5 & 11.9 & & & 23.5 & 12.7 \\
\hline pyroxene & 1.9 & 1.5 & 5.1 & 0.1 & & & 1.9 & 1.4 \\
\hline olivine & 0.8 & 0.8 & 3.0 & & & & 0.4 & 0.6 \\
\hline opaque & 0.3 & 0.2 & 0.6 & & & & 0.1 & 0.2 \\
\hline $\mathrm{SiO} 2$ phase & & & & & & & 0.0 & 0.1 \\
\hline Crystalline Lithics & 4.0 & 1.7 & 6.7 & 1.1 & & & 1.6 & 1.9 \\
\hline Mare Basalt & & & & & & & 0.1 & 0.2 \\
\hline KREEP Basalt & & & & & & & 0.0 & 0.1 \\
\hline Breccias & 34.5 & 8.5 & 47.6 & 13.9 & & & 35.1 & 9.9 \\
\hline Fragmetnal/Vitric Matrix & & & & & & & 16.7 & 7.9 \\
\hline Crystalline matrix & & & & & & & 18.6 & 8.4 \\
\hline Agglutinates & 21.4 & 11.3 & 38.7 & 2.4 & & & 30.9 & 14.0 \\
\hline Glass & 7.3 & 3.2 & 11.2 & 1.2 & & & 6.5 & 3.1 \\
\hline Other & & & & & & & 0.1 & 0.1 \\
\hline Total & 100.0 & & & & & & 100.0 & \\
\hline
\end{tabular}


The Figure of Merit is defined as as a value between 0 and 1. As the two materials become more similar the FoM approaches 1. Mathematically, the FoM is the normalized difference of two composition vectors subtracted from unity. Normalization forces the difference of two composition vectors to lie between 0 and 1 , and subtraction from unity results in a Figure-of-Merit of 1 for a perfect match to 0 for no match at all.

$$
\begin{aligned}
\text { FOM } & =1-\frac{\left\|\mathbf{W}\left(\mathbf{C}_{\text {material A }}-\mathbf{C}_{\text {material B }}\right)\right\|_{1}}{\left\|\mathbf{W} \mathbf{C}_{\text {material A }}\right\|_{1}+\left\|\mathbf{W} \mathbf{C}_{\text {material B }}\right\|_{1}} \\
& =1-\frac{\sum_{i} \mathbf{w}_{i}\left|\left(\mathbf{C}_{\text {material }_{i}}-\mathbf{C}_{\text {material B }}\right)\right|}{\sum_{i} \mathbf{W}_{i} \mathbf{C}_{\text {material }} A_{i}+\sum_{i} \mathbf{W}_{i} \mathbf{C}_{\text {material }} B_{i}}
\end{aligned}
$$

where

$$
\begin{aligned}
& \text { Cmaterial A is the composition vector of the "reference", whose elements are the fractions of the } \\
& \text { various constituents of material } \mathrm{A} \text {; note that the elements of this vector must necessarily } \\
& \text { sum to } 1 \text { (its L1 norm is } 1 \text { ) } \\
& \text { Cmaterial B }_{\text {is }} \text { is the composition vector whose elements are the fractions of the various constituents of } \\
& \text { material B; note that the elements of this vector must necessarily sum to } 1 \text { (its L1 norm is } \\
& \text { 1) } \\
& \text { W is the weighting vector of weights applied to the difference of the material A composition } \\
& \text { vector and the material } \mathrm{B} \text { composition vector. }
\end{aligned}
$$

No weighting was used in these computations, so $\mathbf{W}=1$.

As computed, the Figure of Merit for modal composition may be interpreted as the fraction of material that is the same in both materials. A more detailed exposition of the FoM mathematics may be found Ref. 8 .

The modal, or particle type, composition of a material may be viewed as a vector of the fractions of the various constituents of a material. The elements of a composition vector must necessarily sum to unity (the sum of the fractional parts must equal the whole). Therefore, all published compositions used for this paper have been normalized, when necessary, to unity. Composition may be defined at multiple levels of specificity, starting with basic classes such as lithic fragments, breccias, mineral fragments, glasses, and agglutinates, and then further subdividing each class into sub-constituents as necessary for a particular application. Breccias are further divided into fragmental/vitric and crystalline matrix breccias in Table 1, but for purposes of calculation these are combined into the one category of breccia. For calculation, monomineralic particles are subdivided by mineral type (Table 1). The categories used here do not correspond to the categories in the first release of Figure of Merit software. We used the most detailed common level of classification from the literature samples so as to preserve information. The mathematics, however, are unchanged. 
Table 2. Results of Figure of Merit analysis of 50 Apollo 16 samples. Individual samples were run against the mean of their group and against the mean of the 64001/64002 - our reference composition. Means of groups were also run against each other.

\begin{tabular}{|c|c|c|c|c|c|}
\hline station & sample & $\begin{array}{c}\text { depth, } \\
\text { centimeters }\end{array}$ & $\begin{array}{c}64001 / 02 \\
\text { mean }\end{array}$ & $\begin{array}{c}60009 / 10 \\
\text { mean }\end{array}$ & $\begin{array}{l}\text { Ap16 } \\
\text { surf. } \\
\text { mean }\end{array}$ \\
\hline 10 & $64001 / 02$ mean & core & 1 & 0.81 & 0.86 \\
\hline 10 & $60009 / 10$ mean & core & 0.81 & 1 & 0.84 \\
\hline- & $\begin{array}{l}\text { Ap16 surf. } \\
\text { mean }\end{array}$ & surface & 0.86 & 0.84 & 1 \\
\hline 4 & 64002,261 & 0.50 & 0.89 & & \\
\hline 4 & 64002,262 & 5.50 & 0.95 & & \\
\hline 4 & 64002,263 & 10.50 & 0.94 & & \\
\hline 4 & 64002,264 & 15.00 & 0.79 & & \\
\hline 4 & 64002,265 & 18.50 & 0.88 & & \\
\hline 4 & 64002,266 & 24.50 & 0.93 & & \\
\hline 4 & 64001,370 & 28.00 & 0.95 & & \\
\hline 4 & 64001,371 & 35.50 & 0.95 & & \\
\hline 4 & 64001,372 & 42.50 & 0.92 & & \\
\hline 4 & 64001,373 & 47.00 & 0.97 & & \\
\hline 4 & 64001,374 & 52.50 & 0.91 & & \\
\hline 4 & 64001,375 & 59.50 & 0.91 & & \\
\hline 10 & 60010,1077 & 0.50 & 0.91 & 0.80 & \\
\hline 10 & 60010,1076 & 3.50 & 0.88 & 0.80 & \\
\hline 10 & 60010,1075 & 11.00 & 0.85 & 0.89 & \\
\hline 10 & 60010,1074 & 14.00 & 0.75 & 0.93 & \\
\hline 10 & 60010,3107 & 20.00 & 0.68 & 0.78 & \\
\hline 10 & 60010,1073 & 24.50 & 0.72 & 0.91 & \\
\hline 10 & 60009,454 & 28.80 & 0.79 & 0.92 & \\
\hline 10 & 60009,455 & 42.80 & 0.67 & 0.80 & \\
\hline 10 & 60009,456 & 48.40 & 0.82 & 0.94 & \\
\hline 10 & 60009,457 & 53.30 & 0.41 & 0.53 & \\
\hline 10 & 60009,458 & 58.30 & 0.85 & 0.85 & \\
\hline 1 & 61161 & surface & 0.92 & & 0.85 \\
\hline 1 & 61181 & surface & 0.83 & & 0.74 \\
\hline 1 & 61221 & surface & 0.67 & & 0.77 \\
\hline 1 & 61241 & surface & 0.82 & & 0.86 \\
\hline 2 & 62281 & surface & 0.93 & & 0.83 \\
\hline 4 & 64501 & surface & 0.93 & & 0.82 \\
\hline 8 & 68501 & surface & 0.81 & & 0.78 \\
\hline 11 & 67481 & surface & 0.78 & & 0.90 \\
\hline 11 & 67601 & surface & 0.78 & & 0.92 \\
\hline 11 & 67701 & surface & 0.74 & & 0.87 \\
\hline 11 & 67711 & surface & 0.54 & & 0.67 \\
\hline 11 & 67941 & surface & 0.64 & & 0.77 \\
\hline 13 & 63321 & surface & 0.79 & & 0.91 \\
\hline 13 & 63341 & surface & 0.83 & & 0.95 \\
\hline 13 & 63501 & surface & 0.86 & & 0.89 \\
\hline
\end{tabular}

\section{Results}

Numerical results of all particle type FoM calculations are shown in Table 2. Figure 1 contains both Apollo 16 cores; in it all samples have had FoM scores calculated against the core's mean composition (see Table 2 for scores) and these scores are plotted against depth. The mean FoM scores for each core measured against its own mean composition are: 0.76 for $60009 / 60010$ and 0.92 for $64001 / 64002$. It is evident from Fig. 1 that station 10 core $60009 / 60010$ has the higher internal variance.

At a depth of $53.3 \mathrm{~cm} \mathrm{60009/60010}$ has the lowest FoM score, when measured against its group mean, of any sample in this exercise. This sample has an anomalously high plagioclase particle content of $76.5 \%{ }^{12}$ Ref. 19 also shows that this 60009 sample interval is relatively enriched in $\mathrm{Ca}$ and $\mathrm{Al}$ (two of the main chemical constituents of plagioclase) and depleted in $\mathrm{Fe}, \mathrm{Cr}$, and $\mathrm{Ni}$, and is the most feldspathic regolith sample examined in Apollo core. Another, lesser excursion apparent in 60010 from Fig. 1 is at $20.0 \mathrm{~cm}$, where occurs the highest values of incompatible trace elements (e.g., Th and $\mathrm{Sm}$ ) in the $60009 / 60010$ core along with an enrichment in $\mathrm{Sc}, \mathrm{Cr}$, and $\mathrm{Fe}^{19}$ minerals concentrated in mafic minerals. This sample contains the highest amount of fragments of the mafic mineral pyroxene within the core, at $5.1 \%{ }^{13} \mathrm{~A}$ calculation of the mean FoM for the core 60009/60010 against its mean composition with the $53.3 \mathrm{~cm}$ outlier sample removed yields a mean score of 0.79 - still the lower of the cores tested.

The lowest internal FoM score for the $64001 / 64002$ core is 0.79 at $15.0 \mathrm{~cm}$ depth. This sample contains the highest abundance of monomineralic plagioclase of this core at $42.5 \%$ and the lowest agglutinate $\% .{ }^{15}$ This interval is enriched in Na and Sc. ${ }^{3}$ 


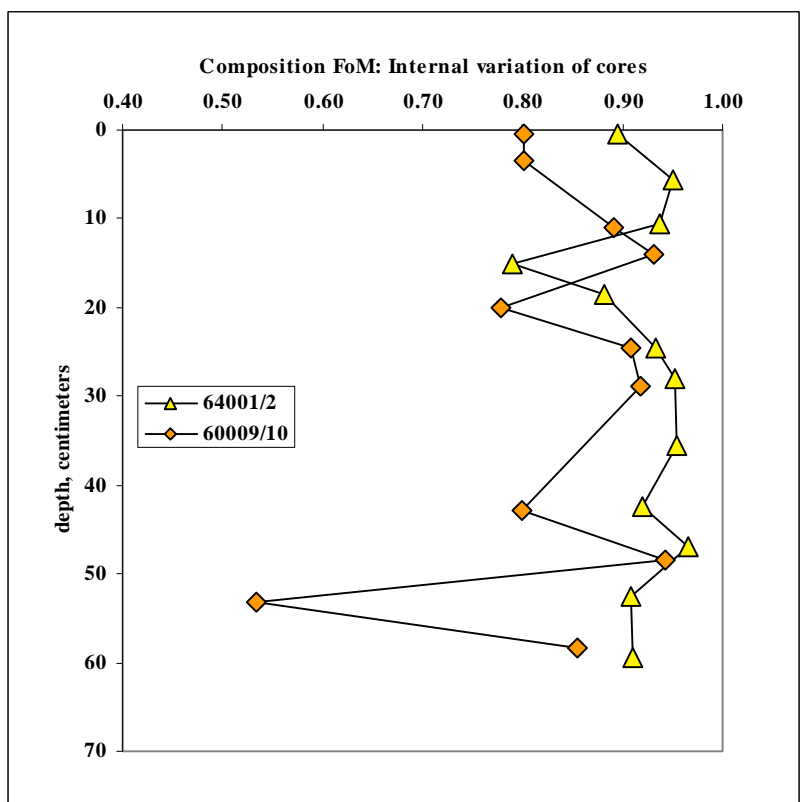

Figure 1. Internal variance of Apollo 16 cores: samples measured against core internal mean composition.

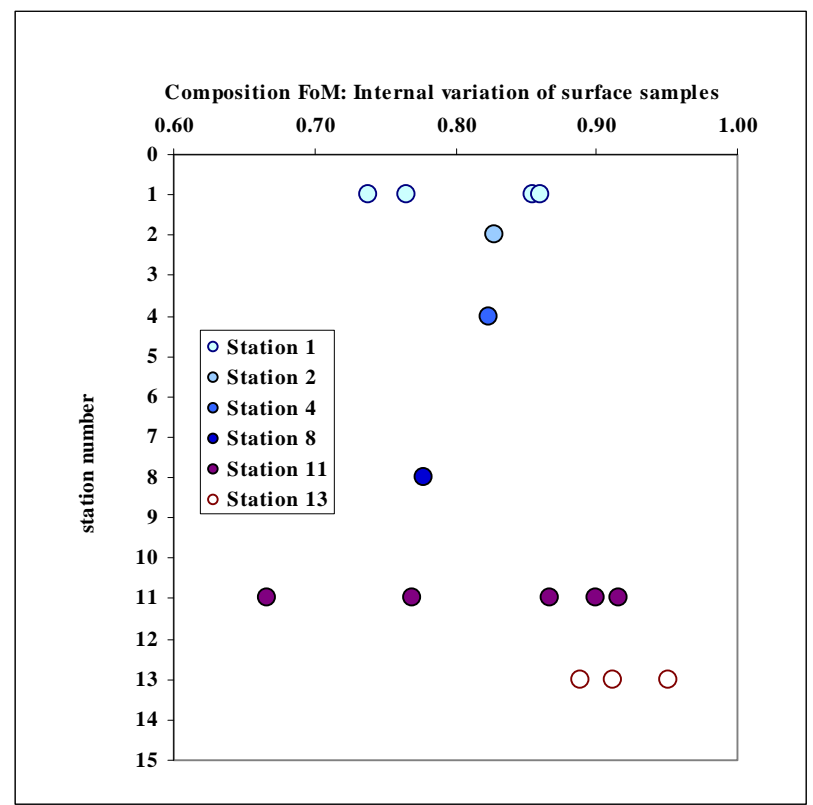

Figure 2. Internal variance of Apollo 16 surface samples measured against their mean group composition.
Figure 2 graphically shows internal variation of particle type FoM scores for the surface samples from Apollo 16 stations. Like the groups shown in Fig. 1, these samples are quantitatively compared to their group's mean composition. In this case the Y-axis is Station number, so the numbers have no correlation to distance. The lowest FoM score shown is for Station 11 sample 67711. This sample has an anomalously high monomineralic plagioclase content of $46.0 \%{ }^{14}$

Figure 3 shows the compositional FoM scores for all samples compared to the mean value of 64001/64002 core, which is our initial general reference material for highlands regolith, plotted against depth. Surface samples are included at $0 \mathrm{~cm}$. The $60009 / 60010$ core maintains the same pattern as in Fig. 1, but with more pronounced excursions. Most surface samples plot with the uppermost samples of the cores but others have scores $<0.70$, overlapping only with the lowest FoM scores of $60009 / 60010$.

One of the parameters that correlates with the compositional FoM score in these Apollo 16 samples is sample maturity. Table 2 contains the results of ferromagnetic resonance (FMR) in index values of $I_{s} / \mathrm{FeO}$. This parameter is a measure of relative regolith maturity. There is a well-demonstrated correlation of $I_{S} / \mathrm{FeO}$ with agglutinate abundance, such that agglutinate modal $\%$ is often used as a proxy for regolith maturity. ${ }^{14}$ Agglutinate \% in the $90-150 \mu \mathrm{m}$ size fraction was studied in Apollo 17 regolith as an examination of regolith maturity. ${ }^{17}$

Figure 4 shows variation in $I_{S} / \mathrm{FeO}$ relative to composition FoM scores measured against the reference mean 64001/64002 composition. The average $I_{s} / \mathrm{FeO}$ of the $64001 / 64002$ core is shown, plotted at FoM $=1$ (since it is the reference material). Although $I_{s} / \mathrm{FeO}$ is not a parameter explicitly incorporated into the modal composition FoM, it is clear that samples are arrayed towards the average $I_{S} / \mathrm{FeO}$ of the reference material. With some scatter, samples less mature than the average 64001/64002 maturity are clearly aligned in a positive slope towards the average composition, and we believe the more mature samples are aligned on a negative slope towards the average composition. Figure 5 shows the same pattern,

but this time by showing agglutinate fraction as a proxy for maturity. 


\section{Conclusion}

We have demonstrated that the composition Figure of Merit captures variance within and between groups of Apollo 16 samples. Variations in FoM correspond to chemical anomalies recognized by other workers. ${ }^{19}$ In addition to chemical data, the variance expressed by the composition FoM also reflects the sample maturity. This correlation between maturity and FoM composition is not surprising, since maturation processes correlate with agglutinization, and agglutinates are one of the most abundant particle types in the lunar regolith, and often the most dominant particle. Of course, as with any variable in the FoM, the correlation will be positive or negative depending on the reference material and the relative abundance in the comparison sample group.

Further correlation of chemical and maturity data with modal data, size distribution data, and shape data may provide efficient estimation of lunar regolith variance for parameters of interest to ISRU and hazard mitigation efforts. To maximize the utility of these estimates of variance, we must gather data on trace minerals and total volume $\%$ modal data by phase in the regolith.

\section{Acknowledgments}

The authors would like to thank the scientists of the Astromaterials Research and Exploration Science (ARES) group at Johnson Space Center, particularly Chuck Meyer, Sue Wentworth, Dan Garrison, and Dave McKay, for their expertise on lunar matters and their aid in finding and assessing data in the literature.

\section{References}

${ }^{1}$ Schrader, C.M., Rickman, D., Mclemore, C., Fikes, J., Wilson, S., Stoeser, D., Butcher, A., and Botha, P., "Extant and Extinct Lunar Regolith Simulants: Modal Analyses of NU-LHT-1M and -2M, OB-1, JSC-1, JSC-1A and -1AF, FJS-1, and MLS-1", Planetary Mining and Science Symposium, Montreal, 2008.

${ }^{2}$ Korotev, R.L., "Compositional Trends in Apollo 16 Soils", Proceedings of the 12th Lunar and Planetary Science Conference, Lunar and Planetary Institute, Houston, 1981, pp. 577-605.

${ }^{3}$ Korotev, R.L., "Comparative Geochemistry of Apollo 16 Surface Soils and Samples from Cores 64002 and 60002 through 60007”, Proceedings of the 13th Lunar and Planetary Science Conference, Part 1, Journal of Geophysical Research, Vol.. 87, Supplement, 1982, pp. A269-A278.

${ }^{4}$ Korotev, R.L., Morris, R.V., and Lauer, H.V., Jr., "Stratigraphy and Geochemistry of the Stone Mountain Core (64001/2)", Proceedings of the 15th Lunar and Planetary Science Conference, Part 1, Journal of Geophysical Research, Vol. 89, Supplement, 1984, pp. C143-C160.

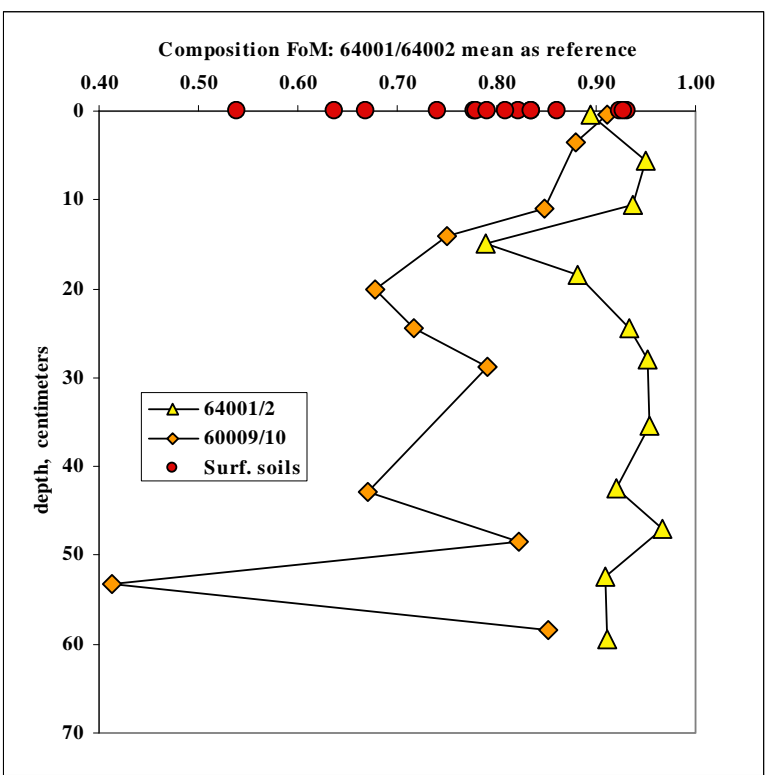

Figure 3. Variance of Apollo 16 samples measured against the mean composition of the 64001/64002 core.

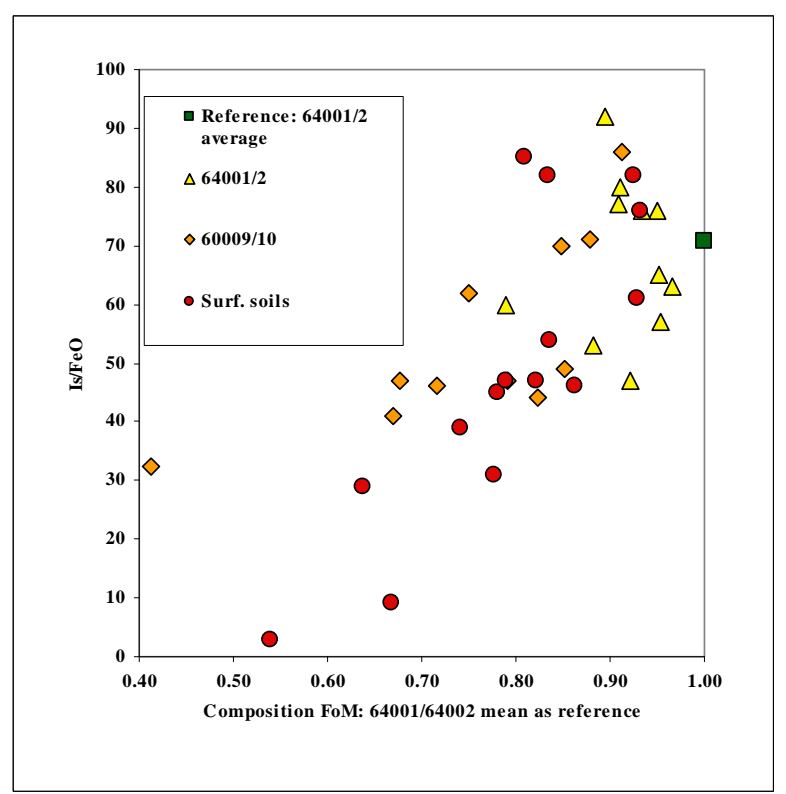

Figure 4. Maturity of Apollo 16 samples plotted against composition FoM measured against reference mean 64001/64002 particle type modal data. 


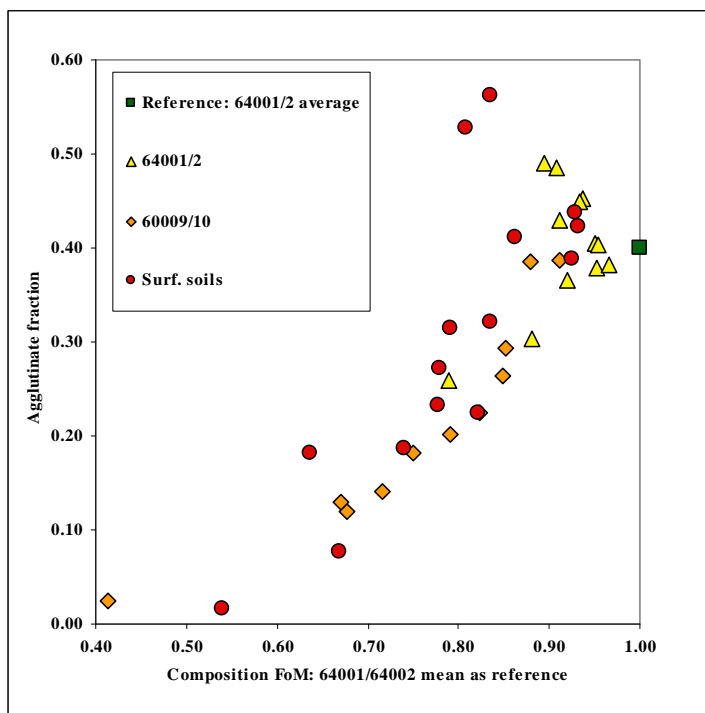

Figure 5. Agglutinate fraction of Apollo 16
samples plotted against composition FoM
measured against reference mean $64001 / 64002$
particle type modal data.

Conference, 1976, pp. 295-313.

${ }^{13}$ Mckay, D.S., Dungan, M.A., Morris, R.V., and Fruland, R.M., "Grain Size, Petrographic, and FMR Studies of the Double Drive Core 60009/10: A Study of Soil Evolution", Proceedings of the 8th Lunar Science Conference, Lunar and Planetary Institute, Houston, 1977, pp. 2929-2952.

${ }^{14}$ Houck, K.J., "Petrologic Variations in Apollo 16 Surface Soils", Proceedings of the 13th Lunar and Planetary Science Conference, Part 1, Journal of Geophysical Research, Vol. 87, Supplement, 1982a, pp. A197-A209.

${ }^{15}$ Houck, K.J., "Modal Petrology of Six Soils from Apollo 16 Double Drive Tube 64002", Proceedings of the 13th Lunar and Planetary Science Conference, Part 1, Journal of Geophysical Research, Vol. 87, Supplement, 1982b, pp. A210-A220.

${ }^{16}$ Basu, A. and Mckay, D.S., "Petrologic Profile of Apollo 16 Regolith at Station 4", Proceedings of the 15th Lunar and Planetary Science Conference, Part 1, Journal of Geophysical Research, Vol. 89, Supplement, 1984, pp. C133-C142.

${ }^{17}$ Mckay, D.S., Fruland, R.M., and Heiken, G.H., "Grain Size and the Evolution of Lunar Soils", Proceedings of the 5th Lunar Conference, Lunar and Planetary Institute, Houston, Vol. 1, 1974, pp. 887-906.

${ }^{18}$ Bowen, N.L., "The Melting Phenomena of Plagioclase Feldspar", American Journal of Science, No. 34, 1913, pp. 577-599.

${ }^{19}$ Korotev, R.L., "Geochemical Stratigraphy of Two Regolith Cores from the Central Highlands of the Moon", Proceedings of the 21st Lunar and Planetary Science Conference, Lunar and Planetary Institute, Houston, 1991, pp. $229-289$. 
AIAA SPACE 2008, 9/11/2008, Paper \#7825

\section{Constraining Particle Variation in Lunar Regolith for Simulant Design}

Christian M. Schrader

BAE Systems, Marshall Space Flight Center, Huntsville, AL, 35805

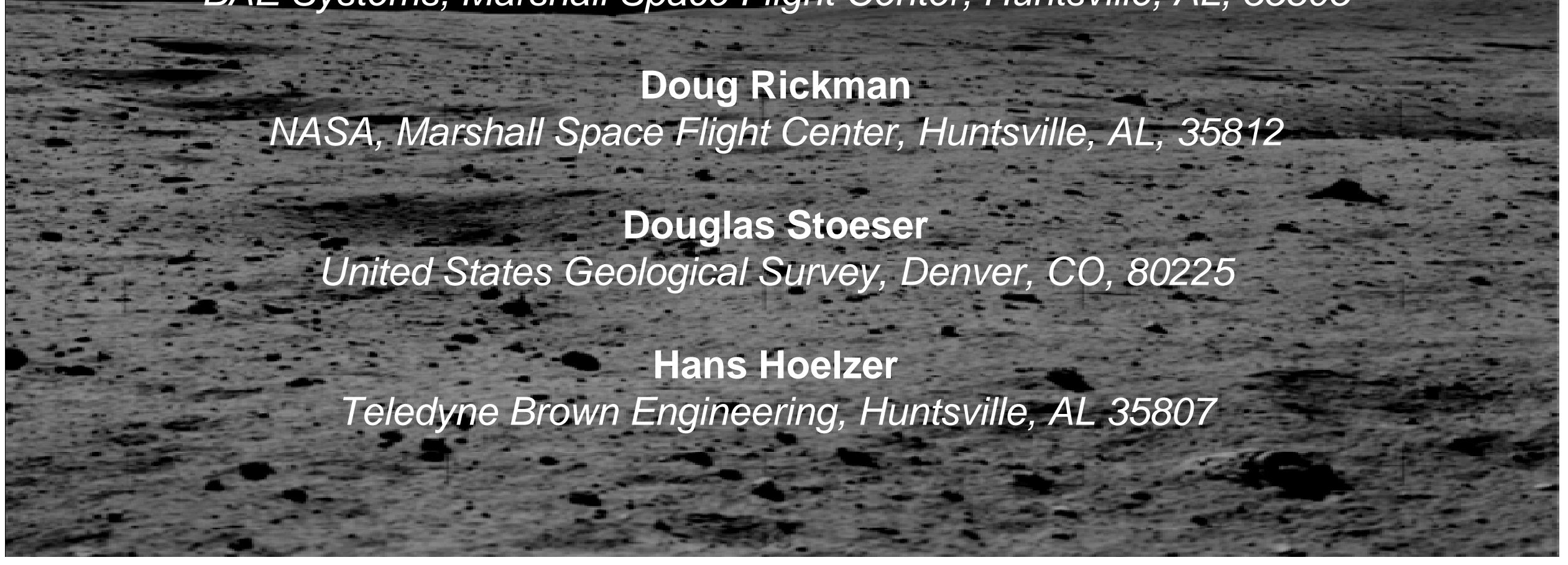




\section{Outline}

- Background

- Figure of Merit

- Variance

- Sample Sites

- Composition data

- Figure of Merit math

- Results and Conclusions

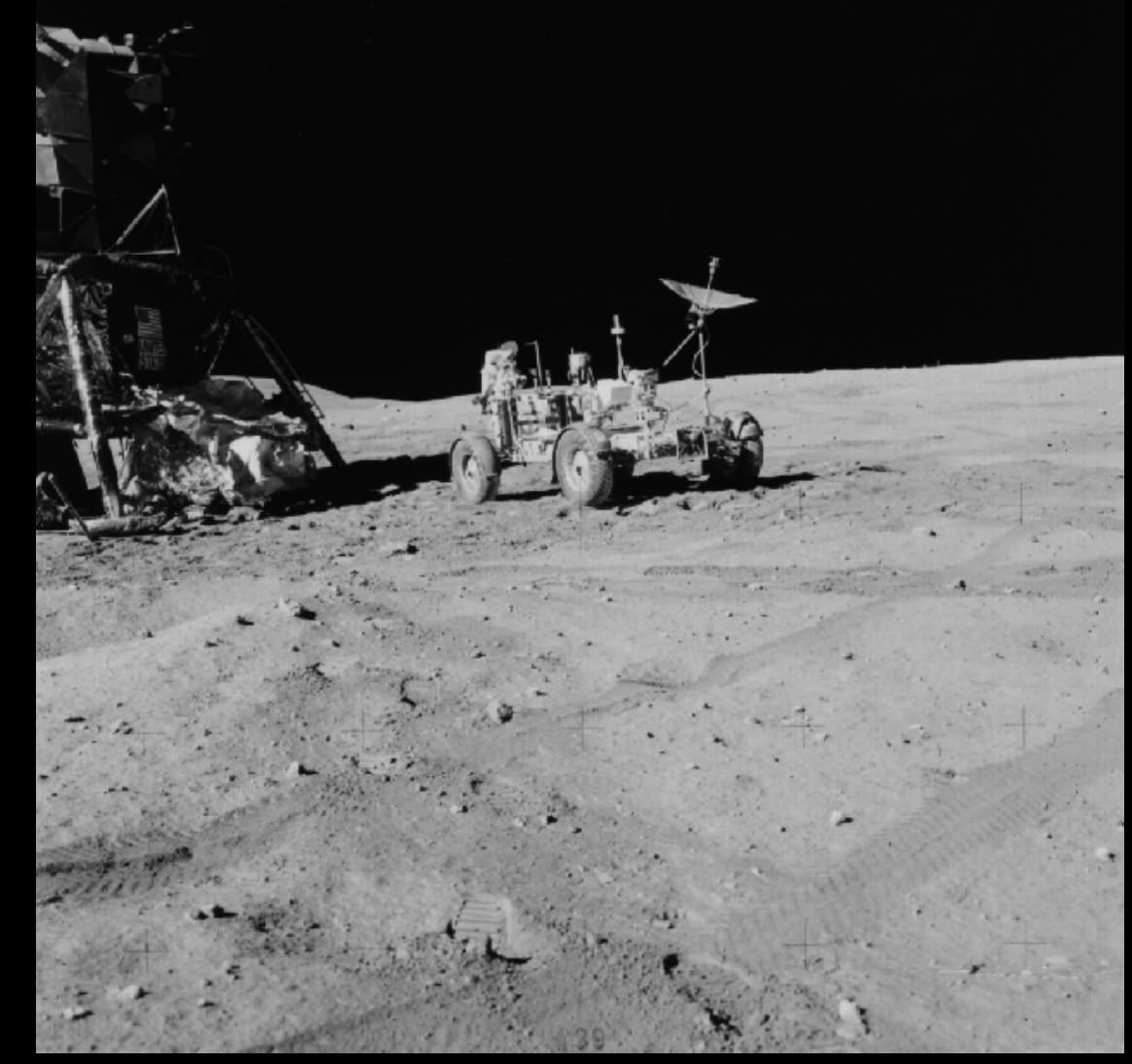




\section{Background: Figure of Merit}

The FoM is a set of algorithms designed to quantitatively compare two granular materials.

1) particle type/composition

2) particle size distribution (PSD)

3) particle shape distribution

4) bulk density characteristics 


\section{Figure of Merit}

- The FoM was developed to compare lunar regolith simulants to lunar reference materials, such as an Apollo sample.

- However, we use it here to compare Apollo 16 samples to one another.

- This stage of work addresses compositional, or particle type, variance only. 


\section{Variance}

Assessing compositional variance of lunar regolith is necessary to provide constraints and "worst case scenarios" for ISRU and hazard mitigation planning. 


\section{Variance: Particle Size (Carrier, 2003)}

- Particle size distribution (PSD) is an important factor in geotechnical behavior and the kinetics of chemical reactions.

- PSD is part of the Figure of Merit.

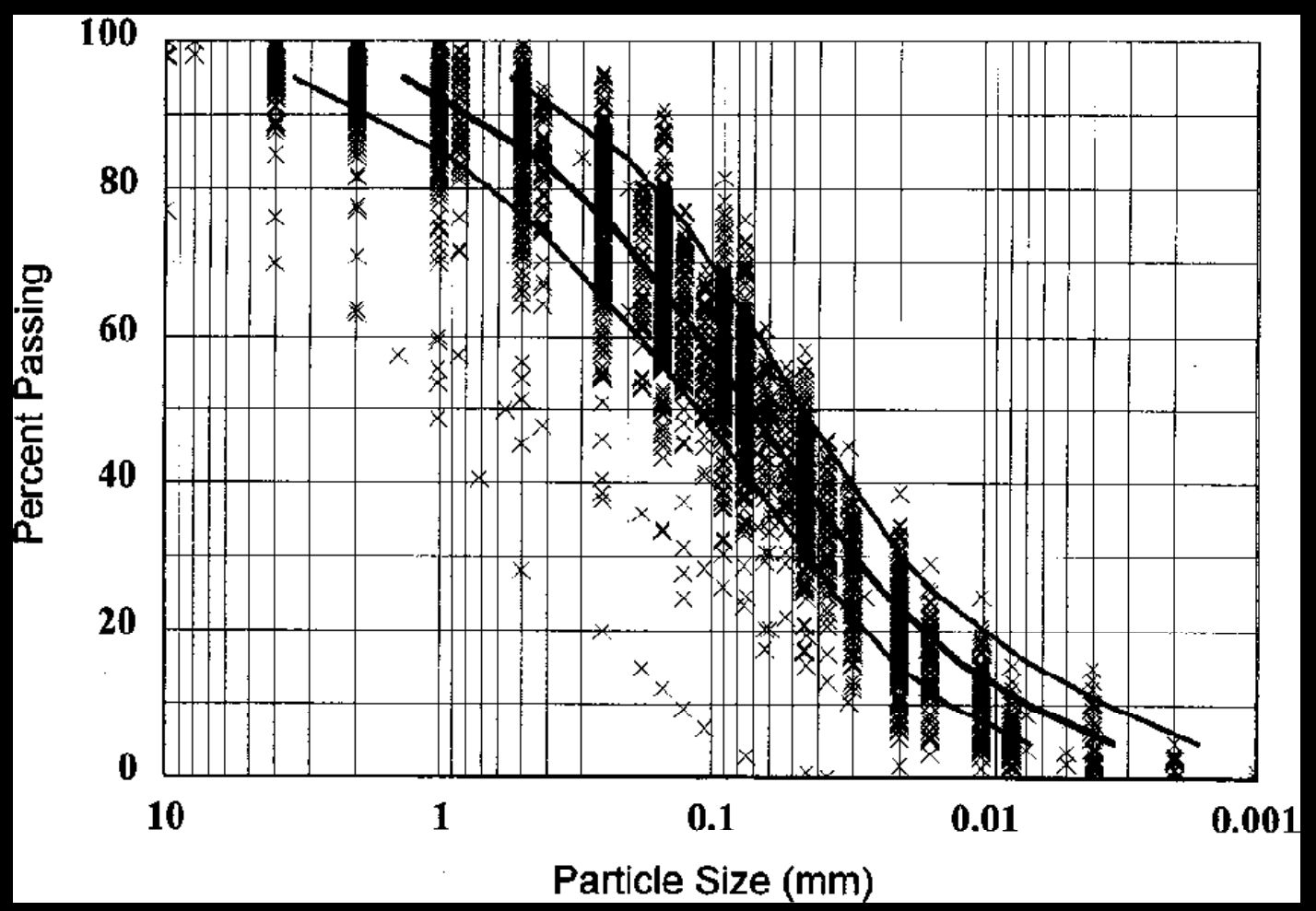




\section{Shape (Liu, 2007)}

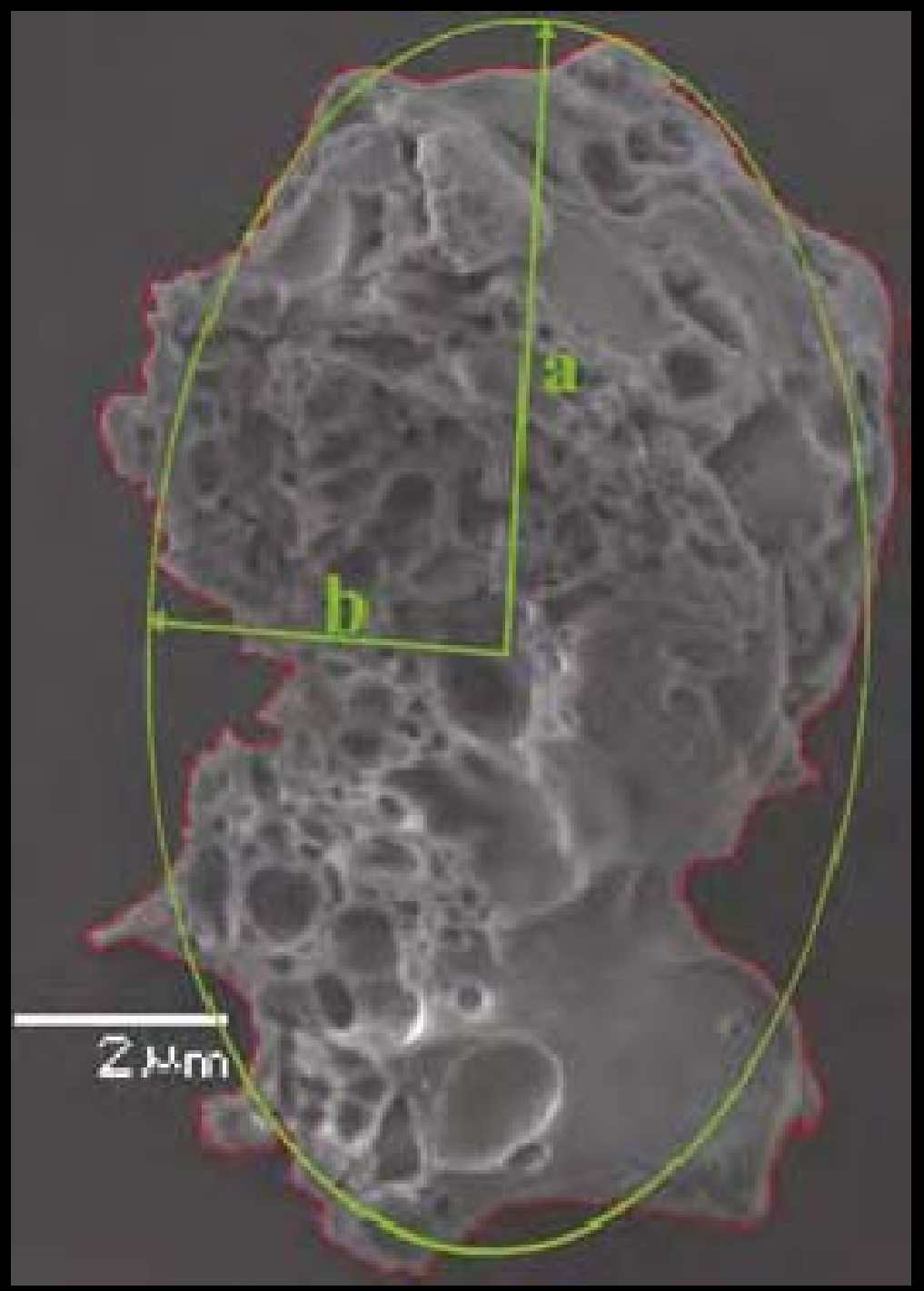

Aspect ratio

Complexity (related to angularity) 


\section{Variance: Major and trace element chemistry}

(Korotev, 1982 and Korotev et al., 1984)

- Regolith chemistry is key to ISRU and to health hazard mitigation.

- Regolith mineralogy is largely derivative of chemistry.

- Mineralogy is part of the particle type
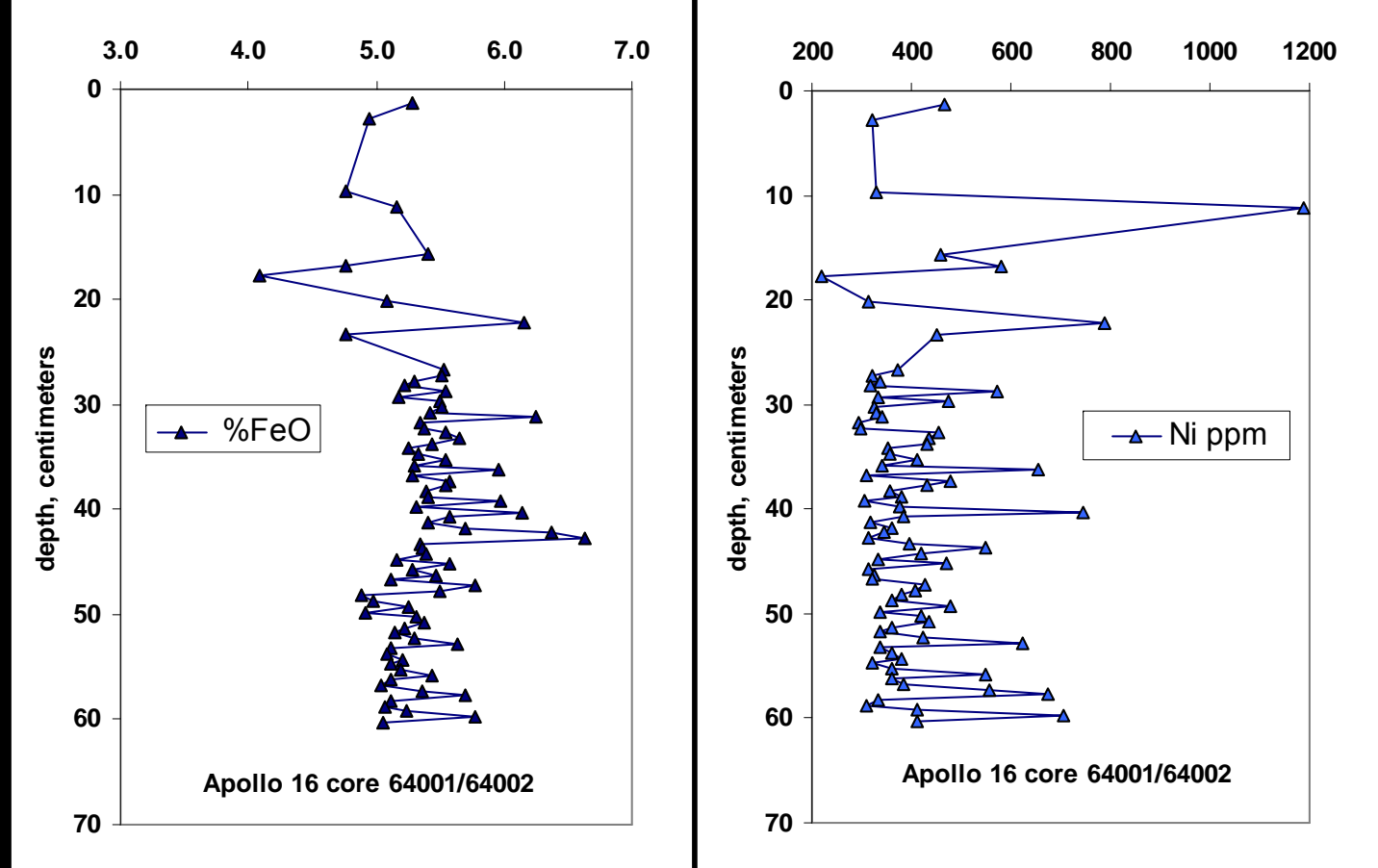
composition Figure of Merit. 


\section{Sampled Sites - Apollo 16}

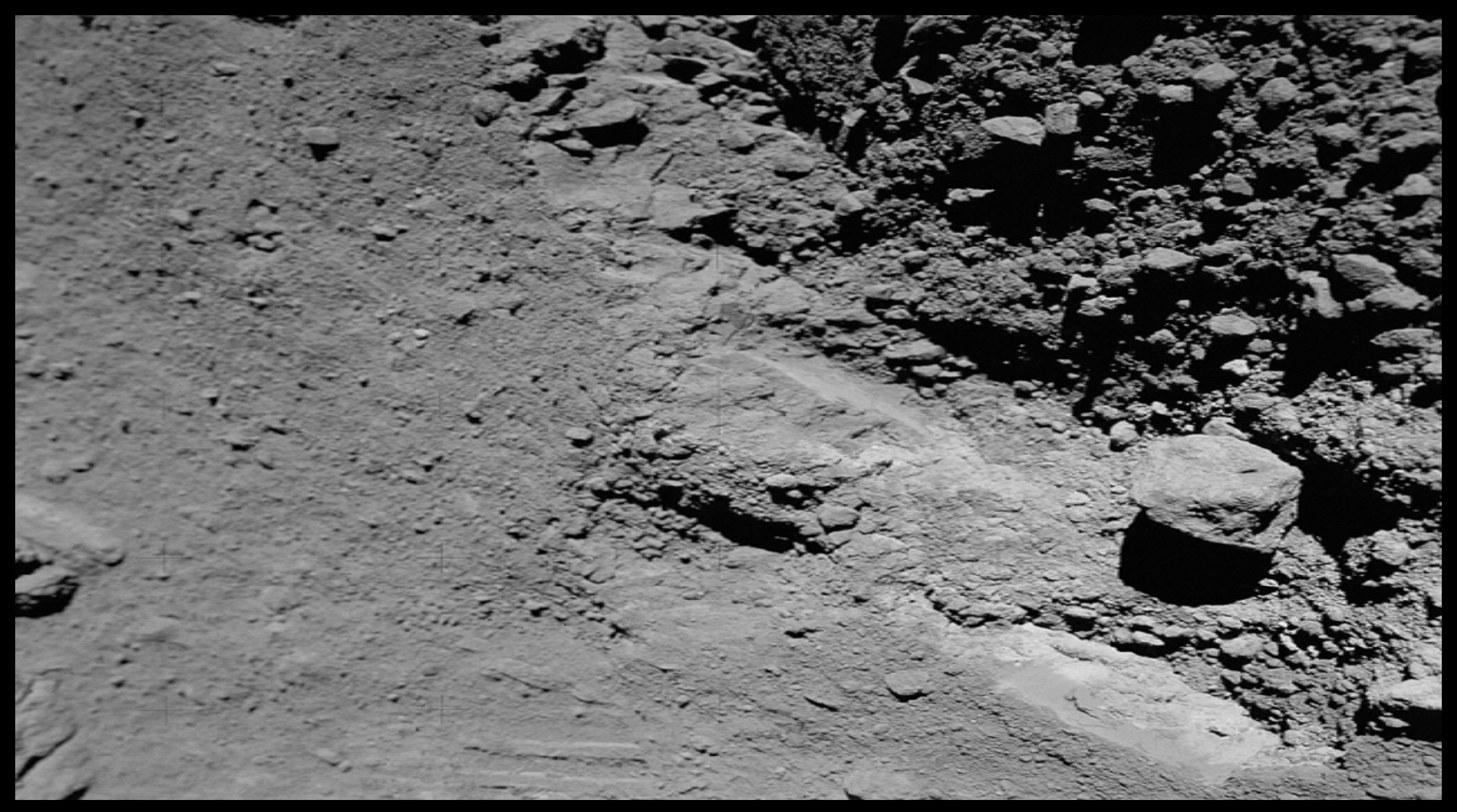




\section{Regolith composition and the simulant project}

We investigate Apollo 16 regolith because it it is the only highlands material available.

We use core samples as reference material for simulant development and evaluation.

Here, we evaluate variance in regolith composition laterally and vertically using core and surface samples.

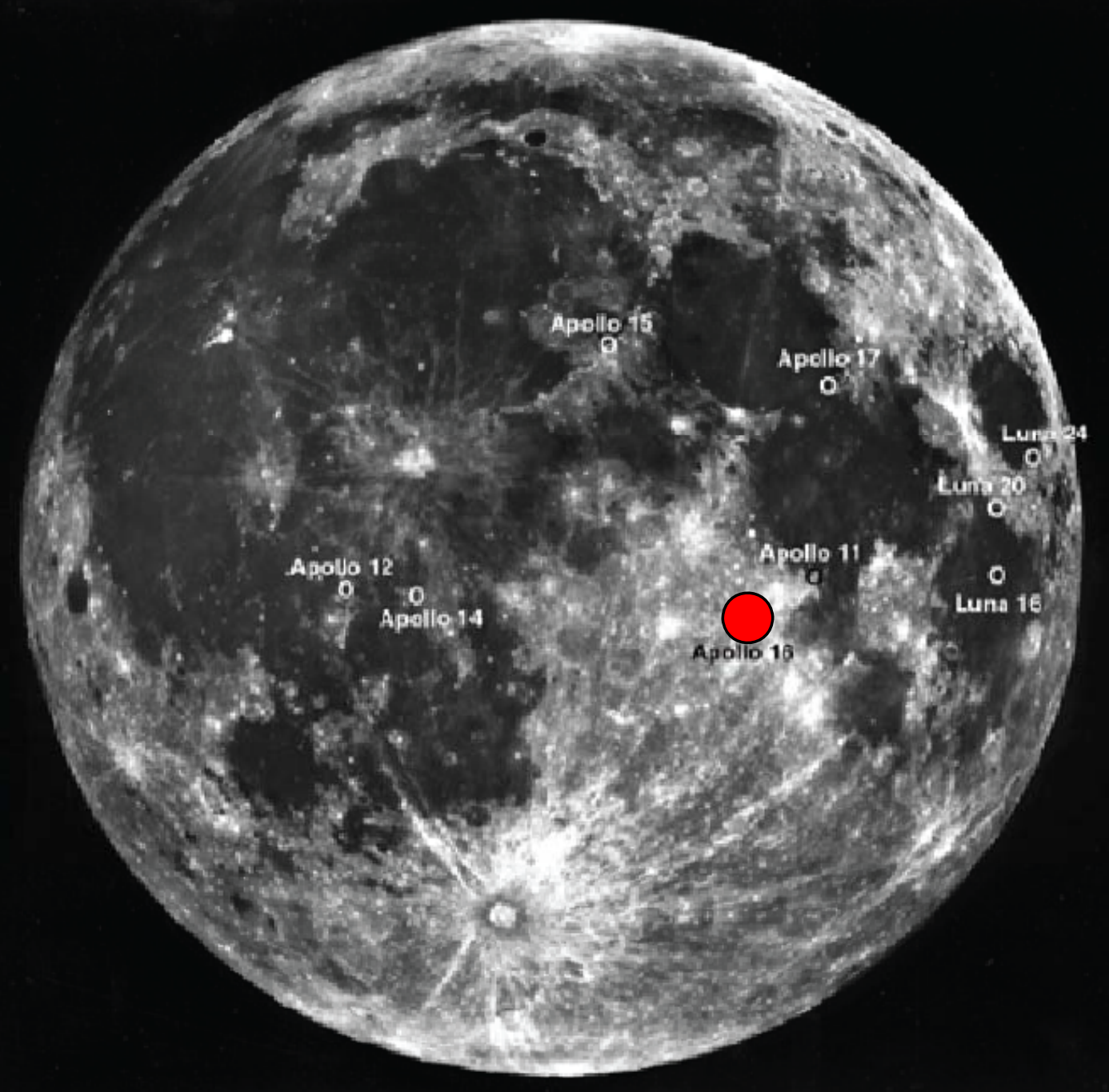




\section{Apollo 16 stations}

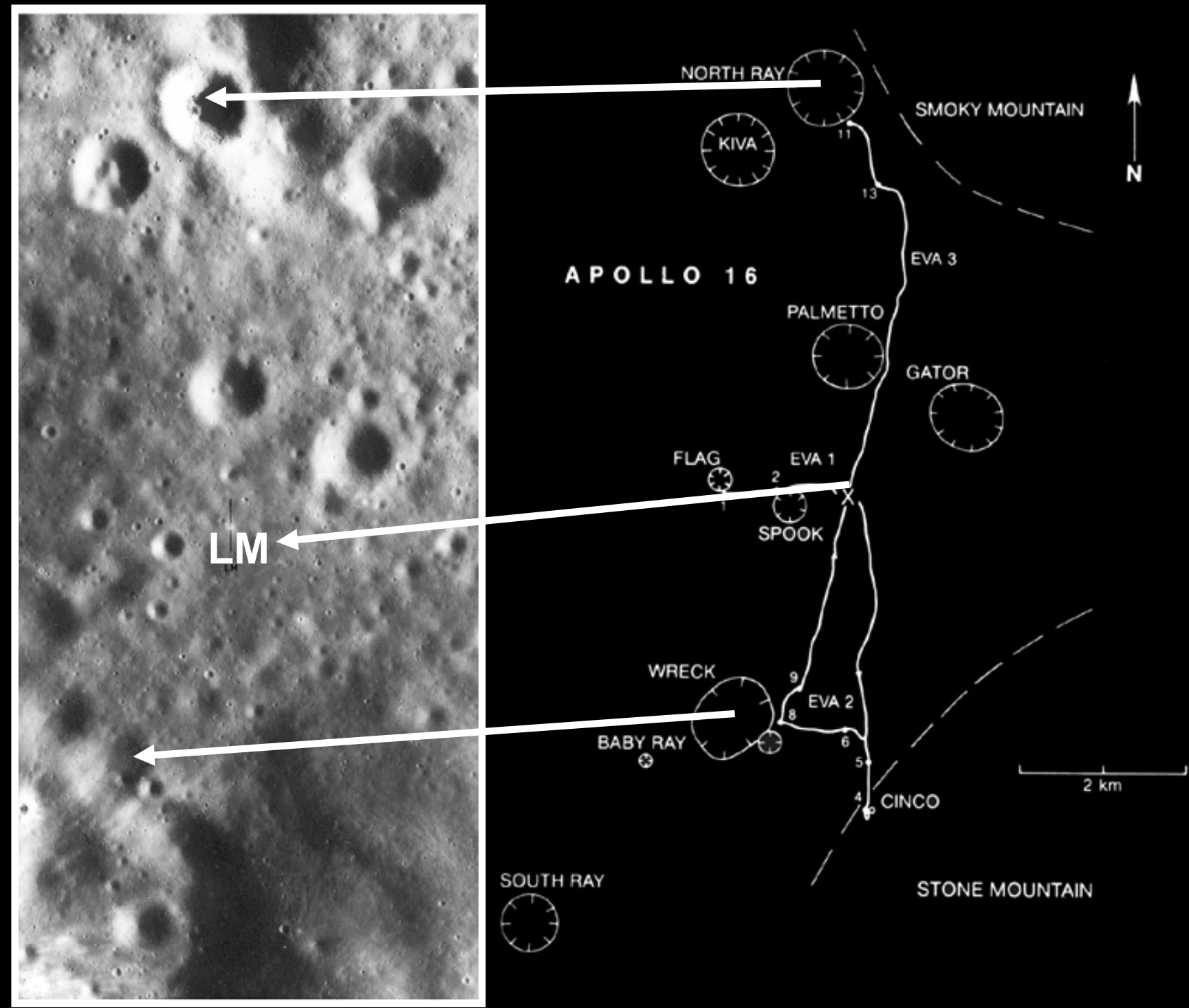




\section{Apollo 16 stations}

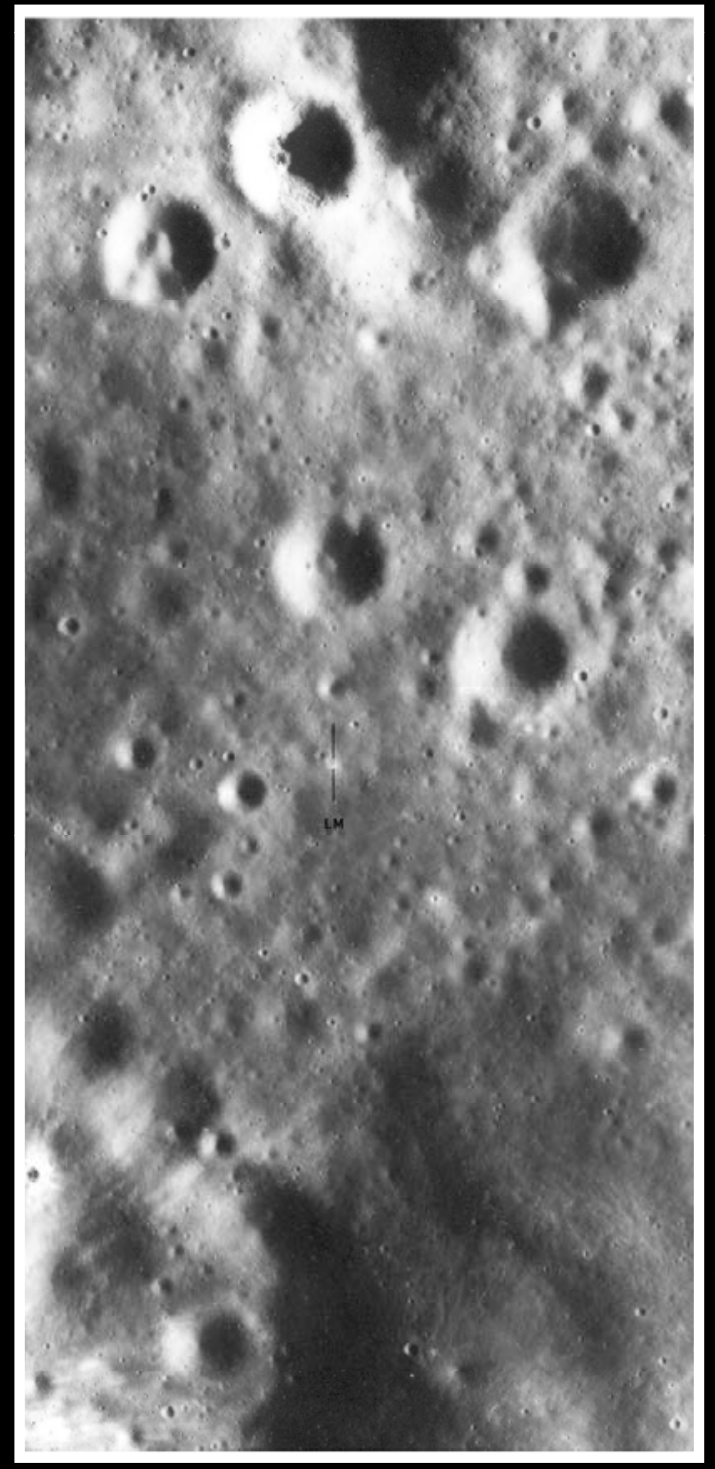

$8 / 27 / 2008$

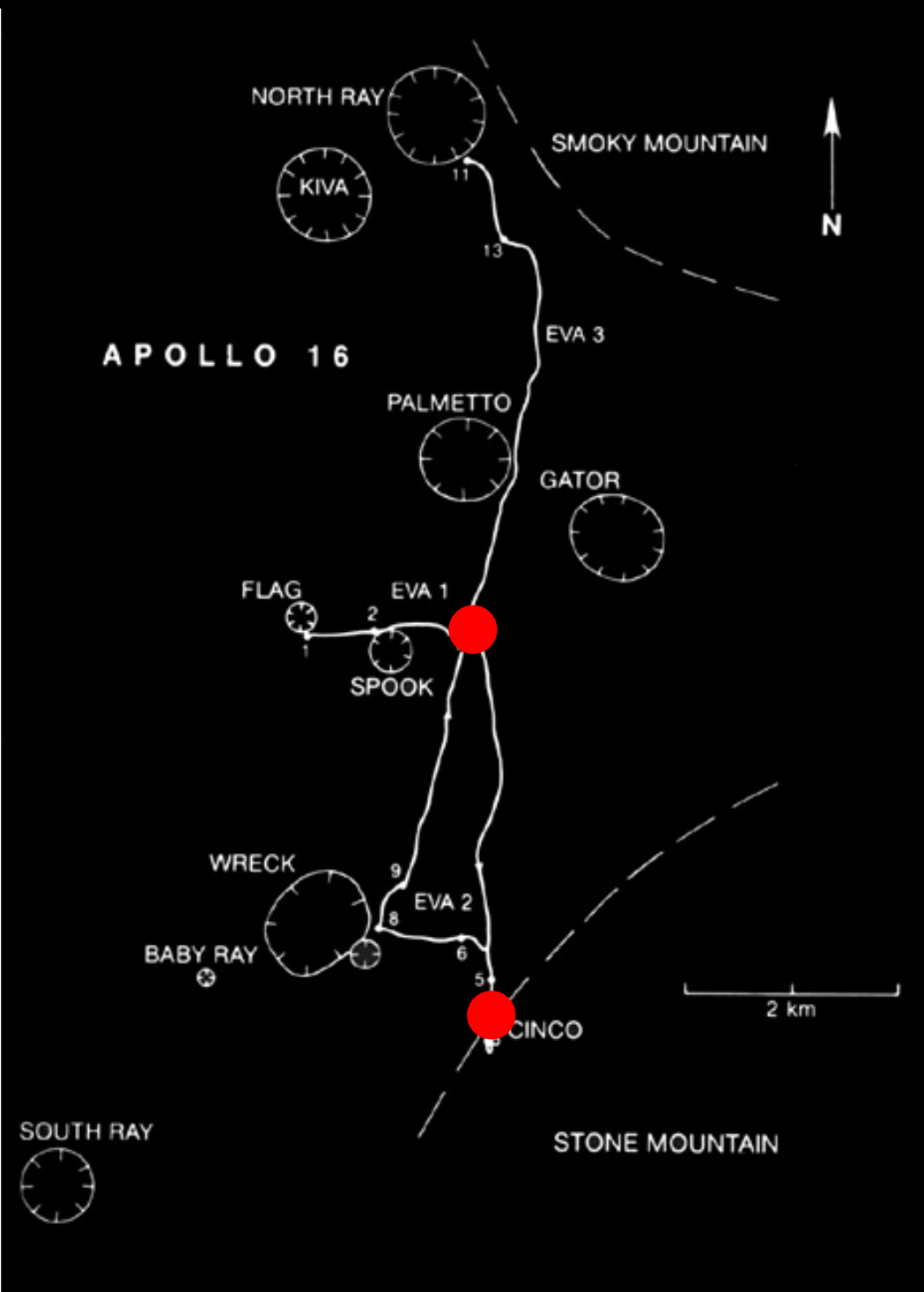

Station 4:

$64001 / 64002(n=12)$

Station 10:

$60009 / 60010(n=11)$ 


\section{Apollo 16 stations}

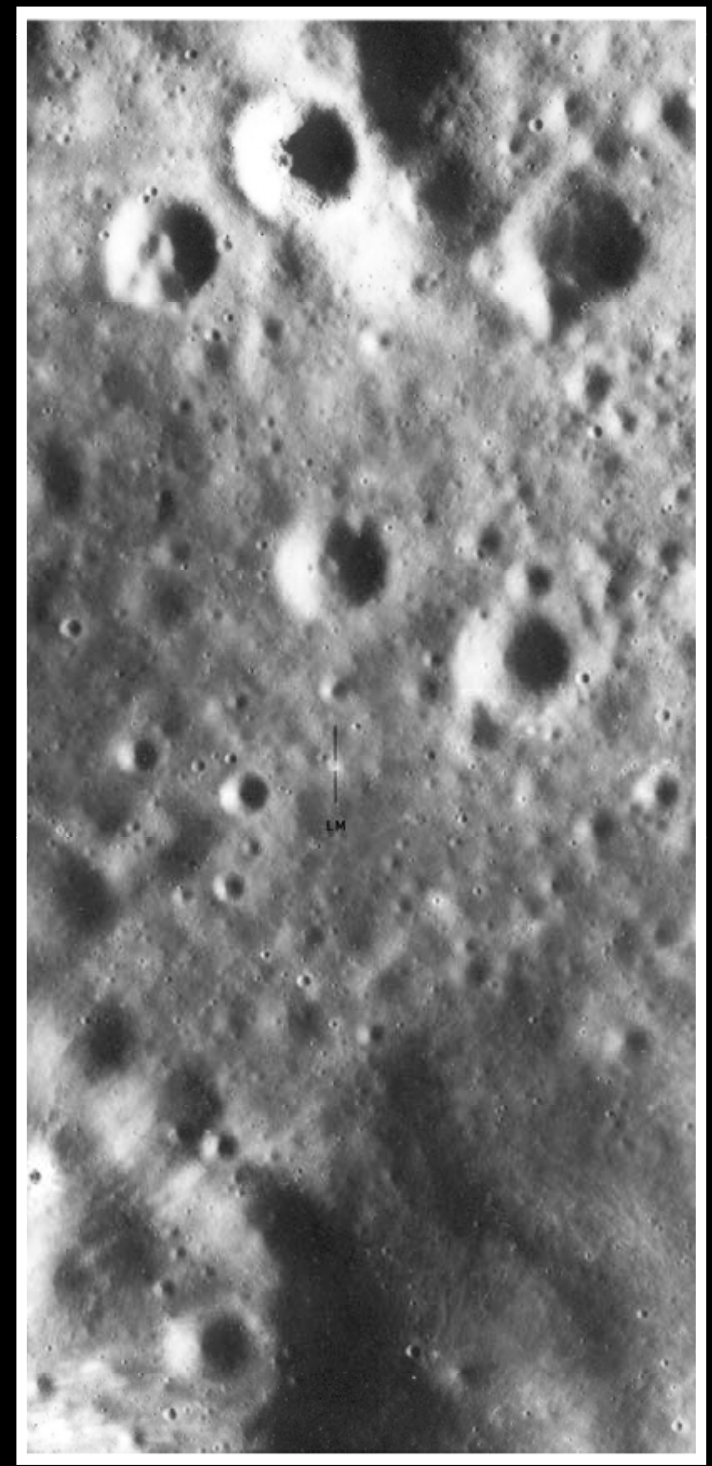

$8 / 27 / 2008$

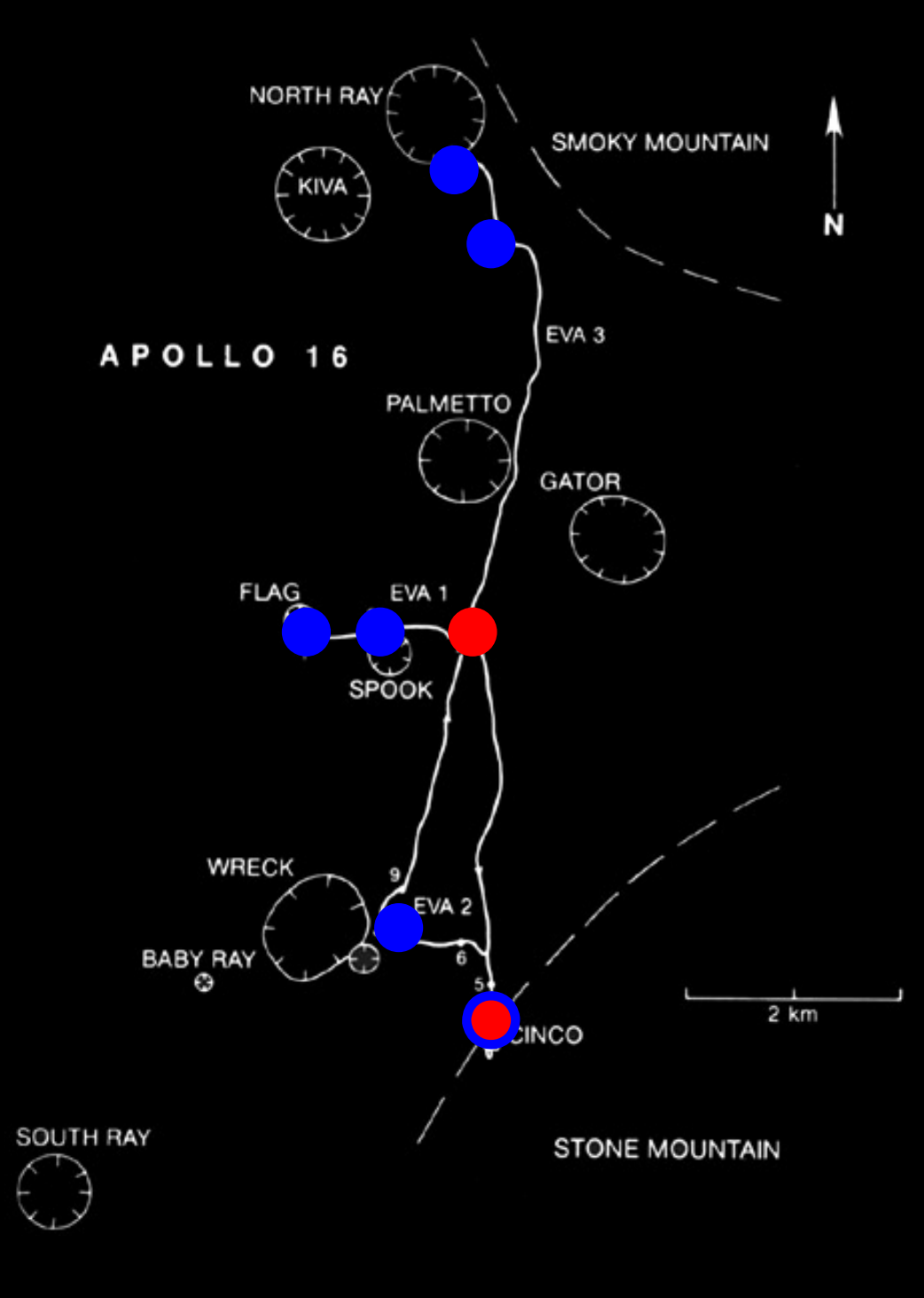

Station 4:

$64001 / 64002(n=12)$ 64501

Station 10:

60009/60010 $(n=11)$

Station 1:

61161, 61181, 61221, 61241

Station 2:

62281

Station 8:

68501

Station 11:

67481, 67601, 67701, 67711,67941

Station 13:

63321, 63341, 63501 


\section{Data: Modal data used in this exercise}

- All data is "particle type" modal data, i.e., a count by volume of grain types.

- this can be gathered by optical microscopy and a large database on Apollo samples exists

- total volume\% data is preferable in some cases but the image analysis necessary has not long been in use

- All data is of the $90-150 \mu m$ fraction.

- some sources contain analyses of multiple size fractions, but all contain at least the 90-150 $\mu \mathrm{m}$

- this fraction is-often studied as representative of the regolith distribution 


\section{Modal data}

- The data used here

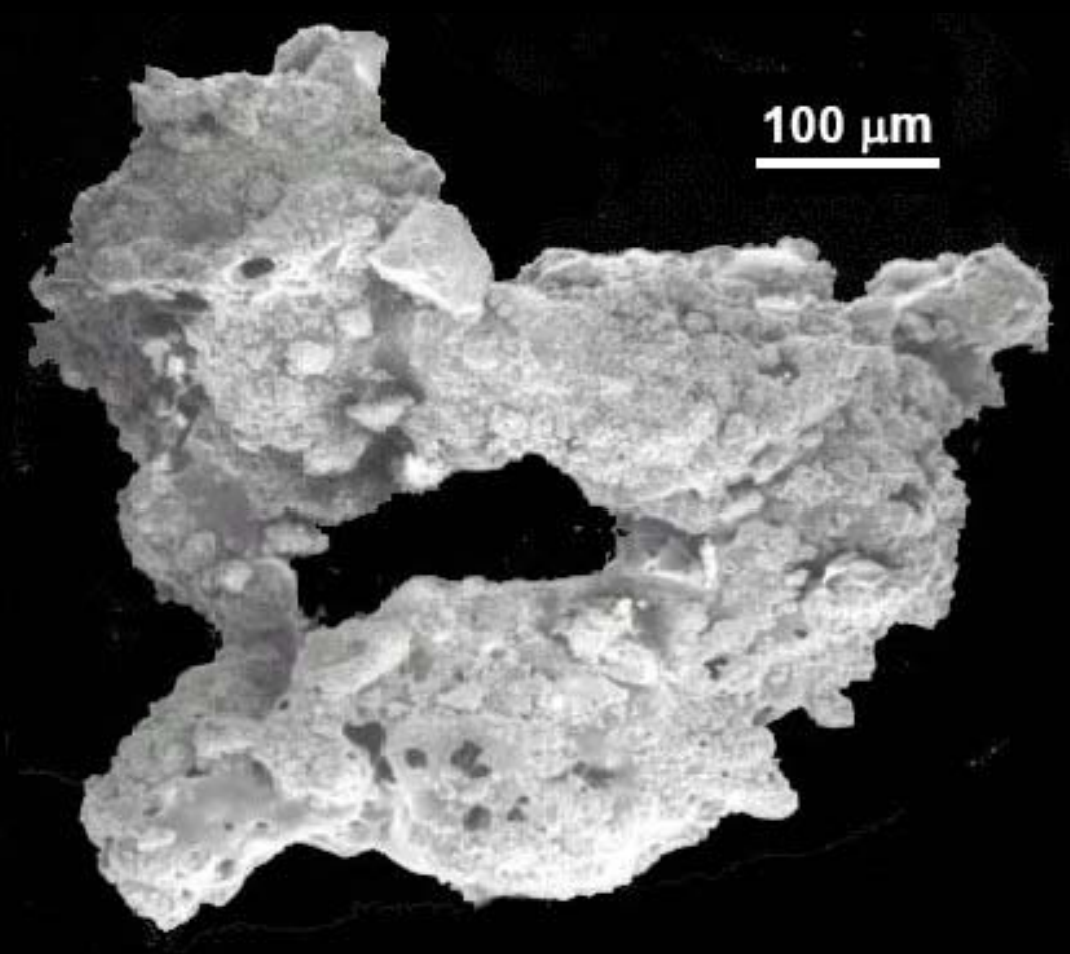
would classify this particle as an agglutinate.

- Image analysis routines on SEM images would parse the constituent glass its minerals. 


\section{Modal data used in this exercise, cont.}

- All data uses a classification system of Basu and McKay (1981), or is convertible to it (e.g., McKay et al., 1977)

- much data is available in the literature but is not directly comparable, due to differing emphasis of attention or particle definition

- The following sources are used:

- McKay et al., 1976 and 1977: 60009/60010 core

- Houck, 1982a: Apollo 16 surface soils from multiple stations

- Houck, 1982b: 64002 core section

- Basu and McKay (1984): 64001 core section 


\section{Average Modal\% of Apollo 16 Regolith Samples}

Monomineralic grains

- Plagioclase

- Pyroxene

- Olivine

- Opaques

Crystalline Lithics (undifferentiated)

- basalts (mare, KREEP)

- anorthosites, etc.

Breccias (undifferentiated)

Agglutinates

Glass (undifferentiated)
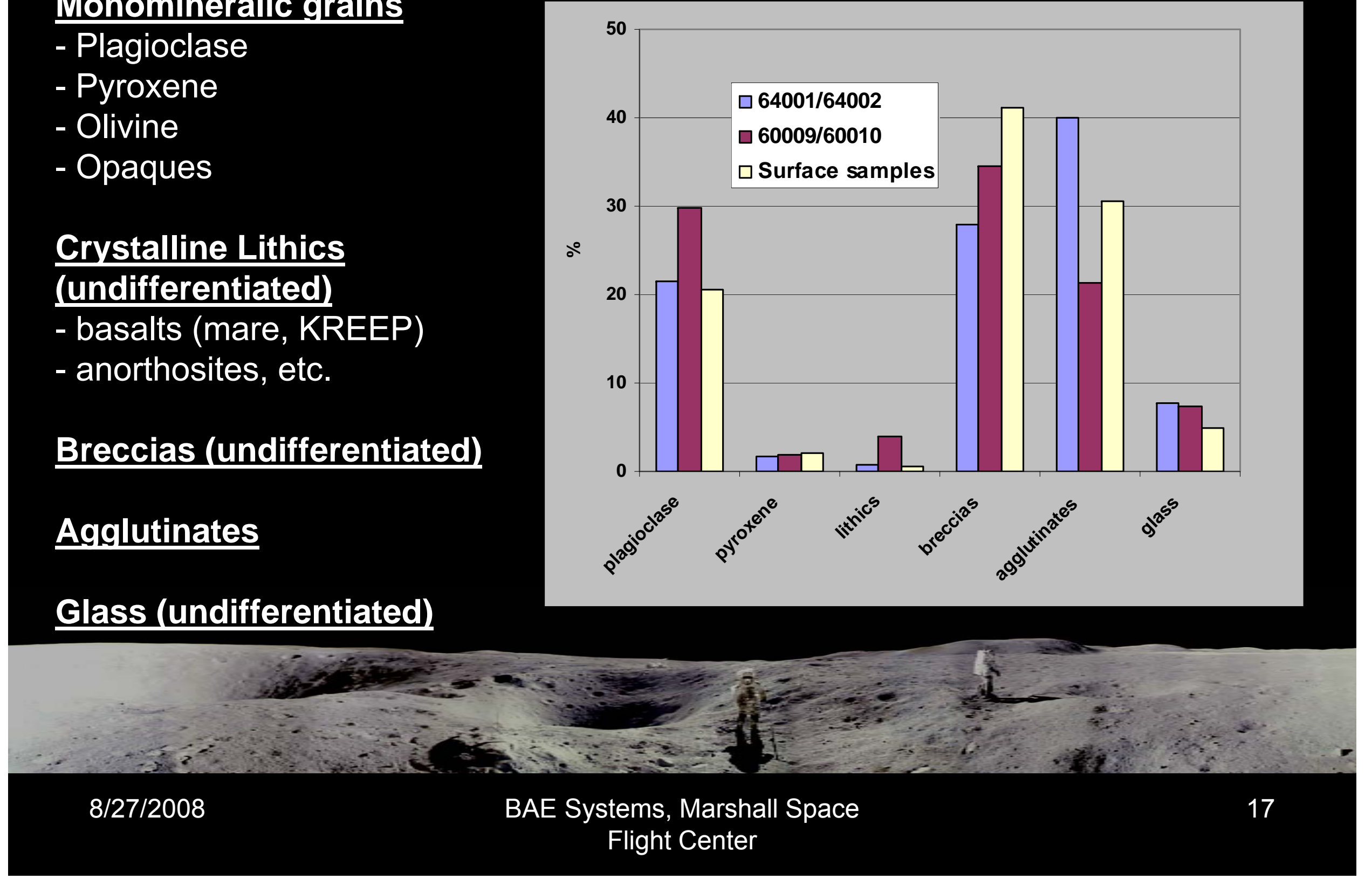


\section{Composition Figure of Merit}

$$
\begin{aligned}
F O M & =1-\frac{\left\|\mathbf{w}\left(\mathbf{C}_{\text {material } A}-\mathbf{C}_{\text {material } B}\right)\right\|_{1}}{\left\|\mathbf{w} \mathbf{C}_{\text {material } A}\right\|_{1}+\left\|\mathbf{w} \mathbf{C}_{\text {material } B}\right\|_{1}} \\
& =1-\frac{\sum_{i} \mathbf{w}_{i}\left|\left(\mathbf{C}_{\text {material } A_{i}}-\mathbf{C}_{\text {material } B_{i}}\right)\right|}{\sum_{i} \mathbf{w}_{i} \mathbf{C}_{\text {material }} A_{i}+\sum_{i} \mathbf{w}_{i} \mathbf{C}_{\text {material }} B_{i}}
\end{aligned}
$$

$\mathrm{C}_{\text {material A: }}$

the composition vector of the "reference", whose elements (minerals, grain types, etc.) must sum to 1

Cmaterial B:

the composition vector of the material to be compared (a simulant, lunar sample, etc.) to the reference material

W:

weighting factor (here it $=1$ ) 


\section{Internal Variance of two Apollo 16 Cores}

64001/64002

FoM composition: 0.79-0.97 mean: 0.92

$60009 / 60010$

FoM composition: 0.53-0.93 mean: 0.83

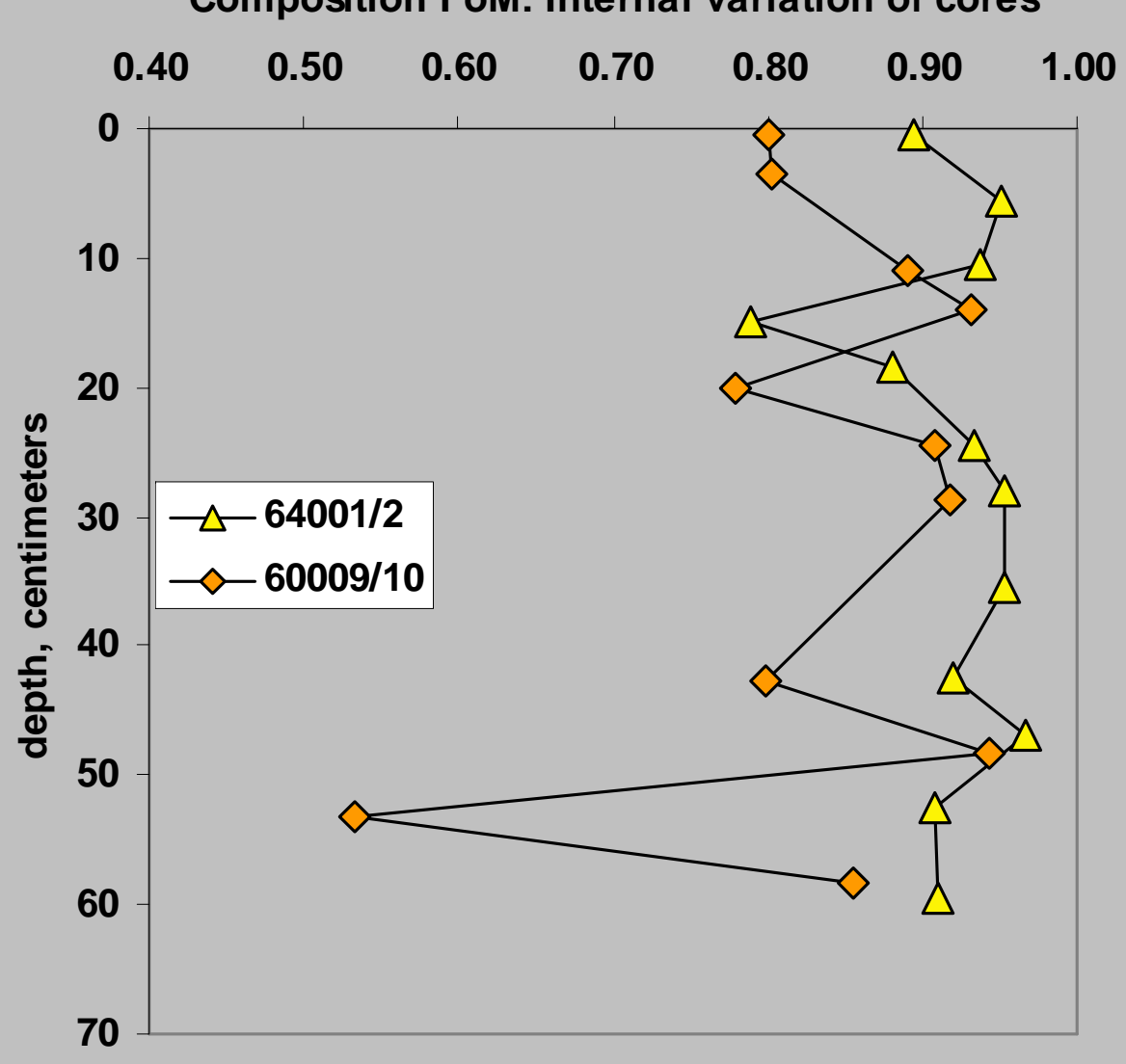




\section{Internal Variance of Apollo 16 Surface Samples}

All Samples

FoM composition: 0.67-0.95 mean: 0.83
Composition FoM: Internal variation of surface samples

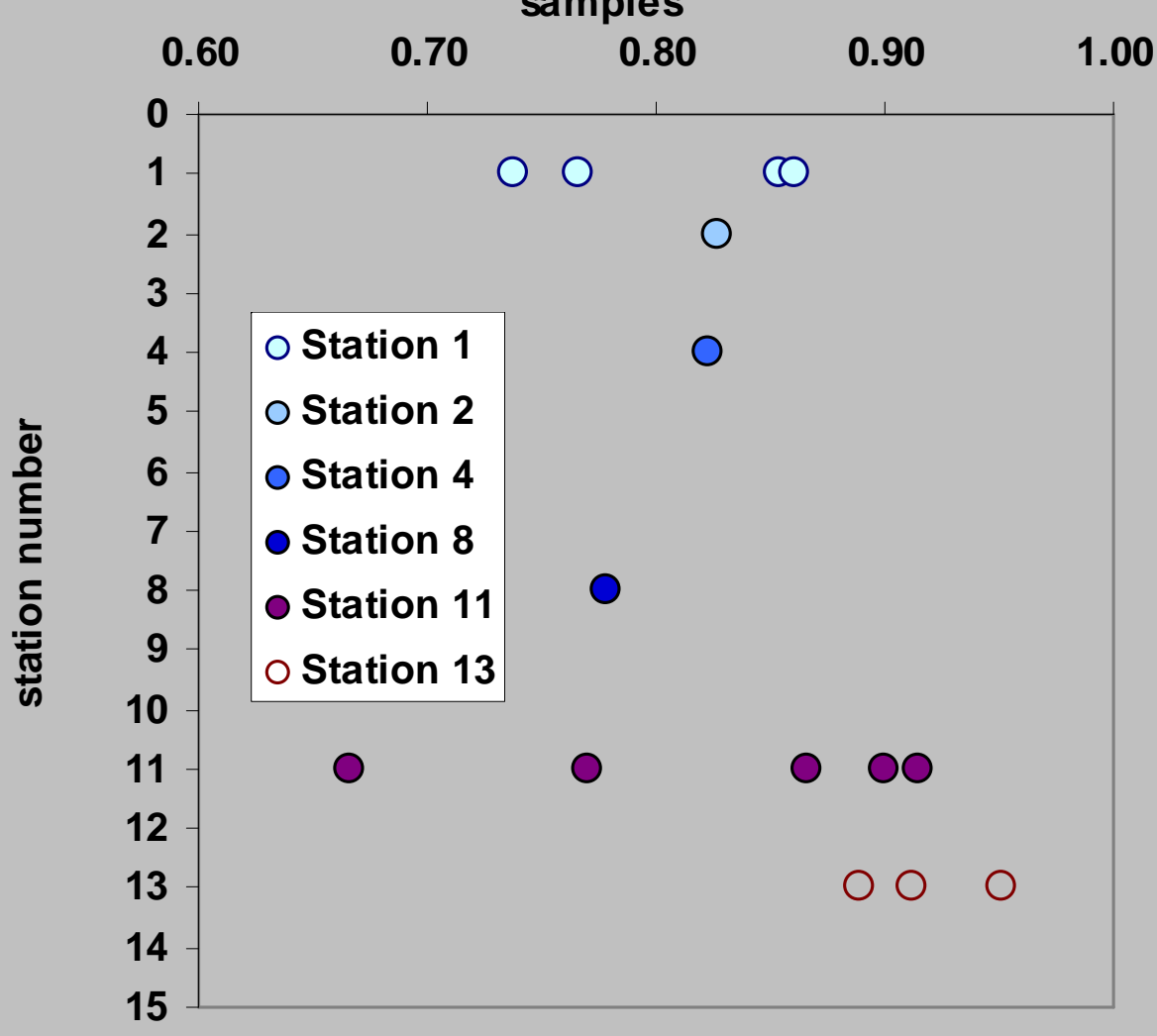




\section{$64001 / 2$ mean as Reference: Apollo 16 Cores and Surface Samples}

64001/64002

FoM composition: 0.79-0.97 mean: 0.92

$60009 / 60010$

FoM composition: 0.41-0.91 mean: $\quad 0.76$

Surface Samples FoM composition: 0.54-0.93 mean: 0.79

Composition FoM: 64001/64002 mean as reference

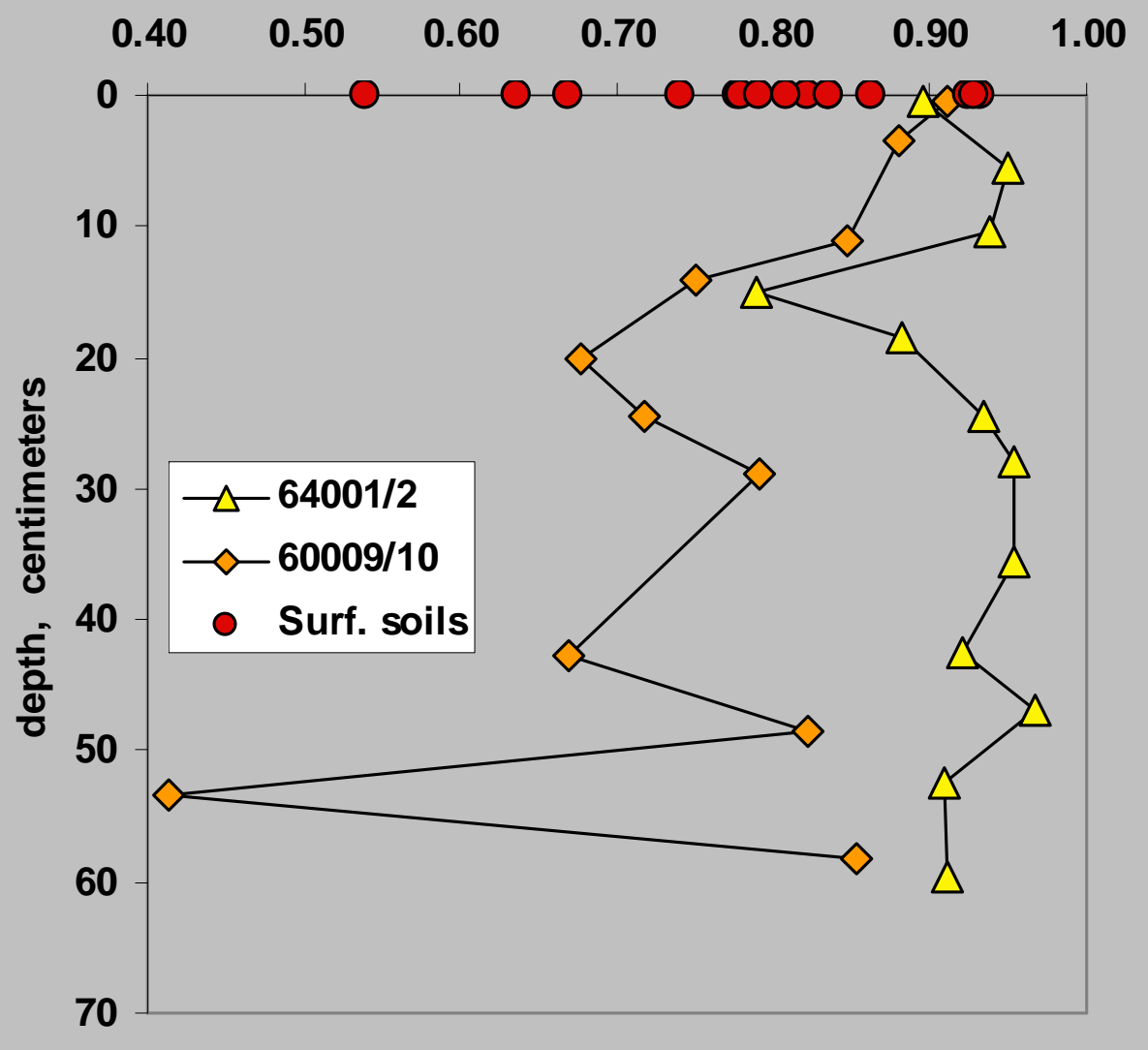




\section{Numbers in parentheses}

are average of whole sample set

60010,3107: FoM 0.68 $5 \%$ pyroxene (2\% avg.) $47 \%$ breccia (35\% avg.) $12 \%$ agglutinate $(31 \%$ avg.) High in $\mathrm{Th}$ and $\mathrm{Sm} ; \mathrm{Fe}$ and $\mathrm{Cr}$

60010,457: FoM 0.41 $76 \%$ plagioclase ( $24 \%$ avg.) High in $\mathrm{Al}, \mathrm{Ca}$, low in $\mathrm{Fe}, \mathrm{Ni}$

Composition FoM: 64001/64002 mean as reference

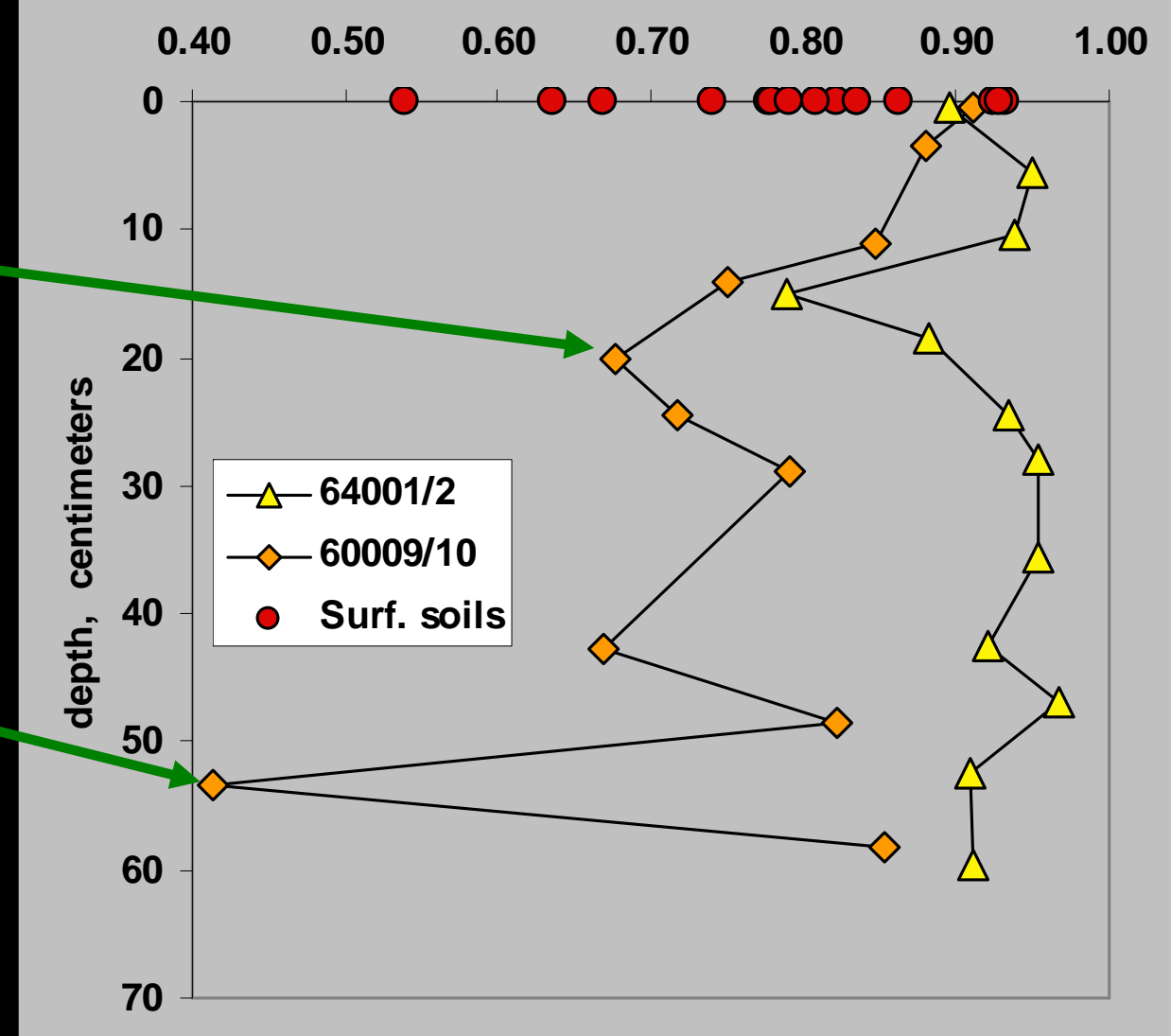




\section{FoM composition and maturity}

- Chemical effects on regolith:

- Fe reduction

- implantation of solar wind particles

This has no effect on the current particle type compositional FoM.

- Maturity has a larger effect on particle type composition. 


\section{Regolith maturity (McKay et al., 1974)}

Path 1 Regolith evolution comminution + agglutinization from micrometeorite impacts

- increased agglutinate\%,

- reduced average grain size,

- decreased lithic\%,

- increased glass\% and monomineralic particle $\%$ in smallest size fractions

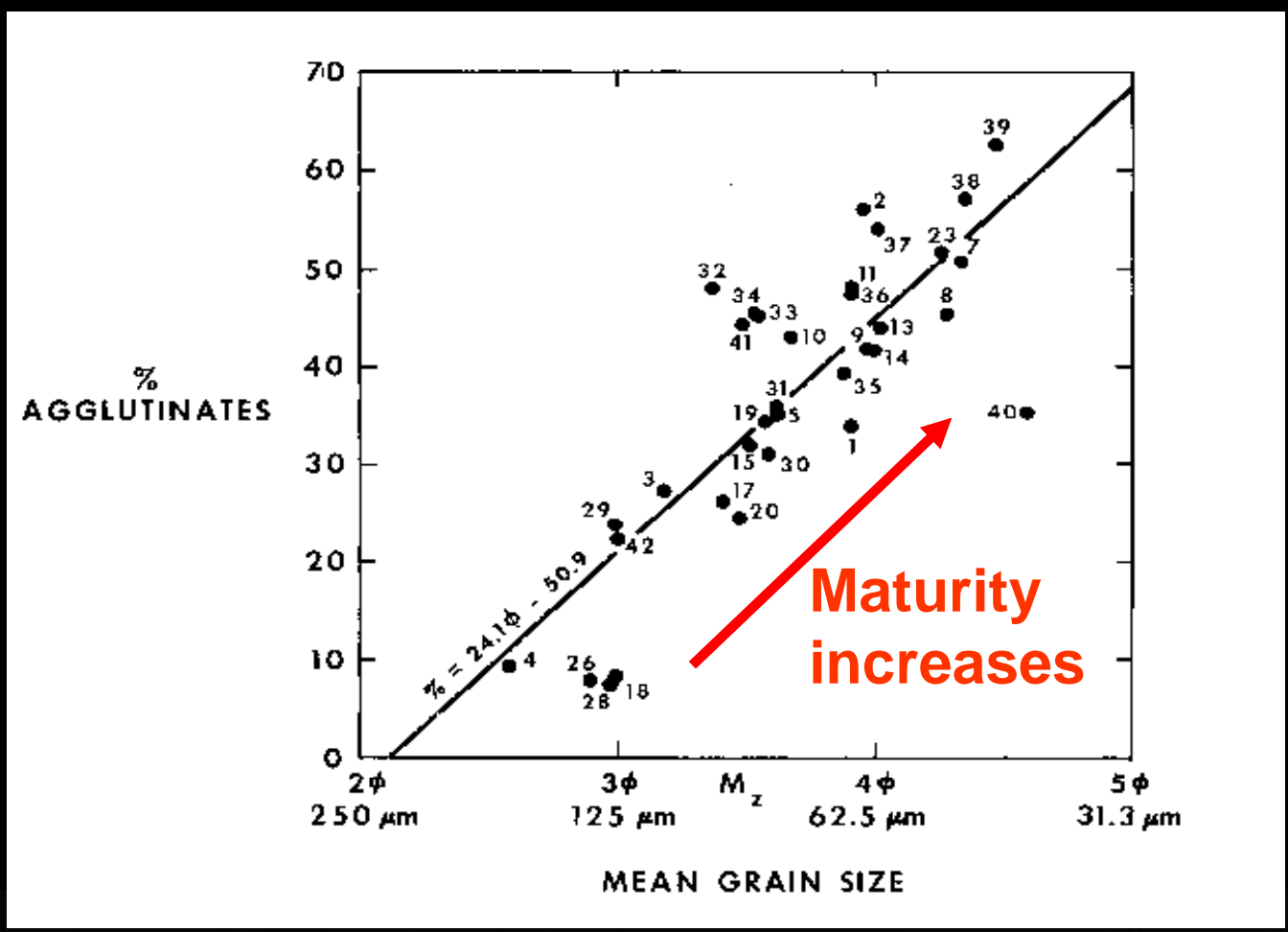

- increased nanophase $\mathrm{Fe}^{0}$ 


\section{Compositional FoM variation by maturity}
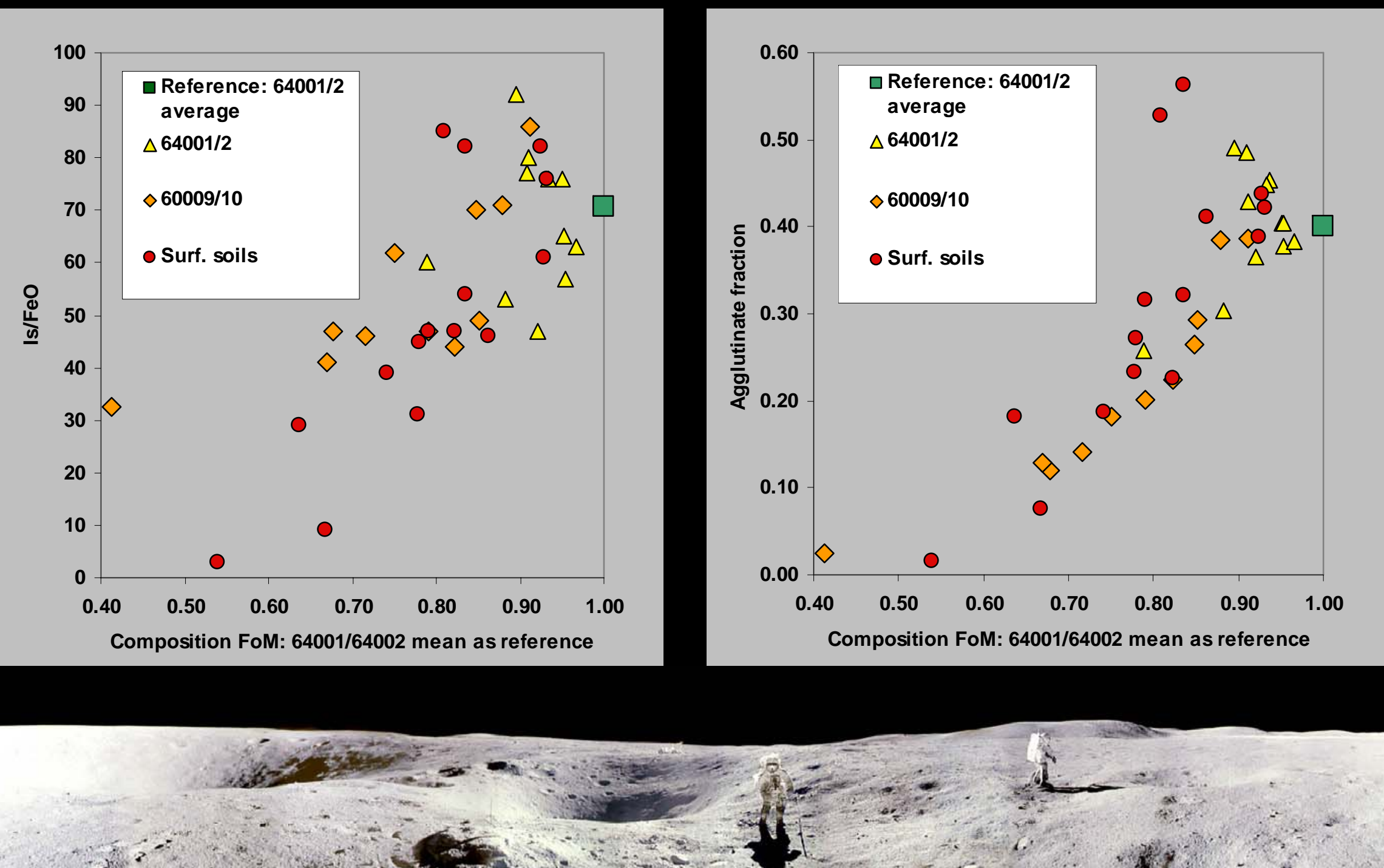


\section{Some Conclusions}

- The reference sample, core 64001/64002, has the lowest internal variance analyzed.

- Available particle type data yields FoM's that are moderately to strongly dependent on sample - maturity.

$\because=1=$

- Combining particle type with data with more - - detailed mineralogical and chemical data will improve variance assessment. 


\section{Further work already underway}

- Incorporating PSD data

- Incorporating at least one more Apollo 16 core $(60013 / 60014)$ into the dataset

- Gathering new detailed mineral/glass modal data from tmage analysis 


\section{References}

Basu, A. and Mckay, D.S., "Classification of Lunar Highland's Submillimeter Particles", in Workshop On Apollo 16, edited by O.B. James and F. Hörz, LPI Technical Report 81-01, Lunar and Planetary Institute, Houston, 1981, pp. 36-39.

Basu, A. and Mckay, D.S., "Petrologic Profile of Apollo 16 Regolith at Station 4", Proceedings of the 15th Lunar and Planetary Science Conference, Part 1, Journal of Geophysical Research, Vol. 89, Supplement, 1984, pp. C133-C142.

Houck, K.J., "Petrologic Variations in Apollo 16 Surface Soils", Proceedings of the 13th Lunar and Planetary Science Conference, Part 1, Journal of Geophysical Research, Vol. 87, Supplement, 1982a, pp. A197-A209.

Houck, K.J., "Modal Petrology of Six Soils from Apollo 16 Double Drive Tube 64002", Proceedings of the 13th Lunar and Planetary Science Conference, Part 1, Journal of Geophysical Research, Vol. 87, Supplement, 1982b, pp. A210-A220.

Korotev, R.L., "Comparative Geochemistry of Apollo 16 Surface Soils and Samples from Cores 64002 and 60002 through 60007", Proceedings of the 13th Lunar and Planetary Science Conference, Part 1, Journal of Geophysical Research, Vol.. 87, Supplement, 1982, pp. A269A278. 


\section{References}

Korotev, R.L., Morris, R.V., and Lauer, H.V., Jr., "Stratigraphy and Geochemistry of the Stone Mountain Core (64001/2)", Proceedings of the 15th Lunar and Planetary Science Conference, Part 1, Journal of Geophysical Research, Vol. 89, Supplement, 1984, pp. C143-C160.

Korotev, R.L., "Compositional Variation in Lunar Regolith Samples - Lateral", LPI Workshop on New Views of the Moon, 1998, pp. 45-46.

Korotev, R.L., "Compositional Variation in Lunar Regolith Samples - Vertical", LPI Workshop on New Views of the Moon, 1998, pp. 47-48.

Mckay, D.S., Dungan, M.A., Morris, R.V., and Fruland, R.M., "Grain Size, Petrographic, and FMR Studies of the Double Drive Core 60009/10: A Study of Soil Evolution", Proceedings of the 8th Lunar Science Conference, Lunar and Planetary Institute, Houston, 1977, pp. 2929-2952.

Mckay, D.S., Fruland, R.M., and Heiken, G.H., "Grain Size and the Evolution of Lunar Soils", Proceedings of the 5th Lunar Conference, Lunar and Planetary Institute, Houston, Vol. 1, 1974, pp. 887-906.

Mckay, D.S., Morris, R.V., Dungan, M.A., Fruland, R.M., and Fuhrman, R., "Comparative Studies of Grain Size Separates of 60009", Proceedings of the 7th Lunar Science Conference, 1976, pp. 295-313.

Liu, Y., Schnare, D., Park, J.S., Hill, E., Eimer, B., and Taylor, L.A., "Shape Analyses of Lunar Dust Particles for Astronaut Toxicological Studies", Proceedings of the 38th Lunar Science Conference, 2007, Abstract no. 1383. 